ARTICLE

\title{
Conformal hexagonal-boron nitride dielectric interface for tungsten diselenide devices with improved mobility and thermal dissipation
}

\author{
Donghua Liu'1,2, Xiaosong Chen 1,2, Yaping Yan 3,4, Zhongwei Zhang 3,4, Zhepeng Jin 1,2, Kongyang Yi(1) 1,2, \\ Cong Zhang ${ }^{1,2}$, Yujie Zheng ${ }^{5}$, Yao Wang ${ }^{6}$, Jun Yang ${ }^{7}$, Xiangfan Xu (1) ${ }^{3,4}$, Jie Chen (1) 3,4, Yunhao Lu6 \\ Dapeng Wei (iD ${ }^{7}$, Andrew Thye Shen Wee (i) ${ }^{5}$ \& Dacheng Wei (iD ${ }^{1,2}$
}

Relatively low mobility and thermal conductance create challenges for application of tungsten diselenide $\left(\mathrm{WSe}_{2}\right)$ in high performance devices. Dielectric interface is of extremely importance for improving carrier transport and heat spreading in a semiconductor device. Here, by near-equilibrium plasma-enhanced chemical vapour deposition, we realize catalyst-free growth of poly-crystalline two-dimensional hexagonal-boron nitride (2D-BN) with domains around 20 $200 \mathrm{~nm}$ directly on $\mathrm{SiO}_{2} / \mathrm{Si}$, quartz, sapphire, silicon or $\mathrm{SiO}_{2} / \mathrm{Si}$ with threedimensional patterns at $300^{\circ} \mathrm{C}$. Owing to the atomically-clean van-der-Walls conformal interface and the fact that $2 \mathrm{D}-\mathrm{BN}$ can better bridge the vibrational spectrum across the interface and protect interfacial heat conduction against substrate roughness, both improved performance and thermal dissipation of $\mathrm{WSe}_{2}$ field-effect transistor are realized with mobility around $56 \sim 121 \mathrm{~cm}^{2} \mathrm{~V}^{-1} \mathrm{~s}^{-1}$ and saturated power intensity up to $4.23 \times 10^{3} \mathrm{~W} \mathrm{~cm}-2$. Owing to its simplicity, conformal growth on three-dimensional surface, compatibility with microelectronic process, it has potential for application in future two-dimensional electronics.

\footnotetext{
${ }^{1}$ State Key Laboratory of Molecular Engineering of Polymers, Fudan University, Shanghai 200433, China. ${ }^{2}$ Department of Macromolecular Science, Fudan University, Shanghai 200433, China. ${ }^{3}$ Center for Phononics and Thermal Energy Science, School of Physics Science and Engineering, and Institute for Advanced Study, Tongji University, Shanghai 200092, China. ${ }^{4}$ China-EU Joint Lab for Nanophononics, Shanghai Key Laboratory of Special Artificial Microstructure Materials and Technology, School of Physics Science and Engineering, Tongji University, Shanghai 200092, China. ${ }^{5}$ Department of Physics, National University of Singapore, Singapore 117542, Singapore. ${ }^{6}$ International Center for New-Structured Materials and School of Materials Science and Engineering, Zhejiang University, Hangzhou 310027, China. ${ }^{7}$ Key Laboratory of Multi-scale Manufacturing Technology, Chongqing Institute of Green and Intelligent Technology, Chinese Academy of Sciences, Chongqing 400714, China. These authors contributed equally: Donghua Liu, Xiaosong Chen. Correspondence and requests for materials should be addressed to Dac.W. (email:weidc@fudan.edu.cn) or to X.X. (email: xuxiangfan@tongji.edu.cn) or to Dap.W. (email: dpwei@cigit.ac.cn)
} 
T ungsten diselenide $\left(\mathrm{WSe}_{2}\right)$, as a two-dimensional (2D) semiconductor with one layer of $\mathrm{W}$ atoms sandwiched between two layers of Se atoms, has been regarded as one of the promising materials in future electronics, spin-electronics, and optoelectronics, owing to its excellent physical, optical, and electrical properties ${ }^{1,2}$. Whereas, the relatively low field-effect mobility is one of the main constraints preventing $\mathrm{WSe}_{2}$ from becoming a competing channel material for practical applications $^{3-5}$. Till now, the room-temperature field-effect mobility of $\mathrm{WSe}_{2}$ grown by chemical vapor deposition (CVD) is normally around $30 \mathrm{~cm}^{2} \mathrm{~V}^{-1} \mathrm{~s}^{-1}$, lower than that required in highperformance electrical or photoelectrical devices ${ }^{3-5}$. Meanwhile, due to the ultra-low thermal conductance of $\mathrm{WSe}_{2}\left(0.05 \mathrm{~W} \mathrm{~m}^{-1}\right.$ $\left.\mathrm{K}^{-1}\right)^{6}$, the requirement for efficient thermal dissipation is another significant factor in practical device application. In an electrical device, charge transport occurs at the interface between the semiconductor layer and the underlying substrate, where joule heating is generated. Thus, it is well known that the device mobility can be largely affected by charge impurities and roughness at the dielectric interface ${ }^{7-15}$. On the other side, the contact thermal interface is normally considered to be the bottleneck for efficient thermal dissipation rather than the material's thermal conductivity itself ${ }^{16-18}$. Therefore, the dielectric interface is of great importance not only for improving the device mobility but also for removing heat from source. Till now, modifying the dielectric interface by self-assembled monolayers, bilayer polymeric dielectrics, plasma treatment, etc. has been developed to improve the device mobility ${ }^{19}$. To solve the interfacial thermal dissipation issue, some attempts such as covalent bonding or forming epitaxial interface have been made ${ }^{20,21}$, however practical applications of these approaches have had limited success due to the high cost, complicated modification process, lack of scalability, negative impact on the device mobility as well as poor compatibility with microelectronic processes. Till now, a simple, scalable, and compatible methodology to modify the dielectric interface for improving both the mobility and the thermal dissipation is still lacking, hampering recent efforts toward highperformance and stable electrical devices based on $\mathrm{WSe}_{2}$ or other $2 \mathrm{D}$ semiconductors.

Hexagonal-boron nitride ( $h$-BN) has attracted much attention in recent years, as this material combines atomic-scale thickness with high dielectric constant $(\sim 4)$, a wide bandgap, chemical inertness, excellent mechanical strength, and flexibility ${ }^{9,14,22}$. The in-plane thermal conductivity is up to $\sim 200$ to $\sim 500 \mathrm{~W} \mathrm{~m}^{-1}$ $\mathrm{K}^{-1}$, several hundred times higher than that of amorphous $\mathrm{SiO}_{2}$ currently used in silicon-on-insulator device ${ }^{23}$. More importantly, 2D $h$-BN (2D-BN) has been normally regarded as a promising dielectric interface material for future electronics ${ }^{9}, 14$. It has an atomically smooth surface without dangling bonds or charge traps, avoiding substrate surface roughness and carrier scattering from charge surface states or impurities. As a result, greatly improved carrier mobility of graphene (up to 100,000 $\mathrm{cm}^{2} \mathrm{~V}^{-1} \mathrm{~s}^{-1}$ ), black phosphorus, MoS , organic crystals has

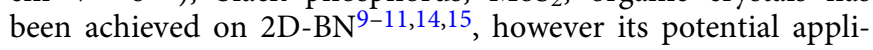
cation in thermal dissipation at the semiconductor/dielectric interface is usually ignored. In the application, large-area 2D-BN needs to be placed on a desired surface. Current preparation methods require $2 \mathrm{D}-\mathrm{BN}$ to be transferred from metals or solutions onto another surface for various applications ${ }^{12,14,24-26}$. The transfer process normally induces impurities, wrinkles, or breakage of the 2D-BN samples, which destroy the ideal vander-Waals dielectric surface and cause interstices or incompact contact at the interface ${ }^{12,14,24-26}$, leading to the possibility of degraded performance or inefficient interfacial thermal dissipation for the $\mathrm{WSe}_{2}$ or other $2 \mathrm{D}$ semiconductorbased devices.
Although CVD on metal catalyst surface such as $\mathrm{Cu}, \mathrm{Ni}, \mathrm{Pt}$, and $\mathrm{Cu}-\mathrm{Ni}$ alloy can produce highly crystalline large-area $2 \mathrm{D}$ $\mathrm{BN}^{27-30}$, it still requires the transfer process and a high growth temperature of $900-1000^{\circ} \mathrm{C}$. Recently, a few attempts on catalystfree CVD have been made to grow $2 \mathrm{D}-\mathrm{BN}$ directly on $\mathrm{SiO}_{2} / \mathrm{Si}^{31}$ or sapphire ${ }^{32}$. However, these processes require extremely high growth temperature above 1100 or $1400^{\circ} \mathrm{C}$, respectively. In an industrial-scale production, high temperature implies large energy consumption, high cost, and a decrease in compatibility with microelectronics fabrication processes. Plasma-enhanced CVD (PECVD) is a widely used industrial technology, which has high compatibility with current microelectronics fabrication process. To solve this problem, PECVD is particularly attractive, since the high energy plasma environment can decompose the precursor molecules at room temperature, thus enabling lowtemperature growth of boron nitride $(\mathrm{BN})$ materials directly on various surfaces ${ }^{33-35}$. Without metal catalysts, structural defects readily form at the edges and terminate the crystal growth. As a result, amorphous $\mathrm{BN}$, disordered $h$-BN, or cubic-BN thick films are normally obtained by PECVD ${ }^{33-35}$, with a thickness about tens or hundreds of nanometers and a quality lower than that required for device applications. Till now, the catalyst-free growth of 2D-BN (mono-layered or few-layered) by PECVD is still absent.

Herein, we find that efficient crystal growth of 2D-BN takes place in a near-equilibrium state between the competition of etching and growth in PECVD. Based on this finding, we develop a near-equilibrium PECVD (ne-PECVD) to modify the dielectric interface, which realizes catalyst-free growth of uniform poly-crystalline 2D-BN with domains around 20-200 nm directly on $\mathrm{SiO}_{2} / \mathrm{Si}$, quartz, sapphire, silicon, or even $\mathrm{SiO}_{2} / \mathrm{Si}$ with three-dimensional (3D) structures at a temperature as low as $300^{\circ} \mathrm{C}$, hundreds of degrees lower than that previously reported for $2 \mathrm{D}-\mathrm{BN}$ growth. The thickness is precisely controlled from monolayer to four-layer by the growth time. After modification, the substrates have a smooth, atomically clean, and tightly contacted conformal van-der-Waals dielectric interface, which can be directly used to grow $\mathrm{WSe}_{2}$ by CVD $\left(\mathrm{CVD}-\mathrm{WSe}_{2}\right.$ ) for field-effect transistors (FETs). As a result, the device has an improved mobility around $56-121 \mathrm{~cm}^{2} \mathrm{~V}^{-1} \mathrm{~s}^{-1}$, higher than that on bare $\mathrm{SiO}_{2} / \mathrm{Si}\left(2-21 \mathrm{~cm}^{2} \mathrm{~V}^{-1} \mathrm{~s}^{-1}\right)$ and the reported results of CVD-WSe 2 FETs on $\mathrm{SiO}_{2} / \mathrm{Si}^{3-5}$, and exhibits high stability with increased saturated power density up to $4.23 \times 10^{3} \mathrm{~W} \mathrm{~cm}^{-2}$. Both experimental and simulation results show that the conformal 2D-BN produced by ne-PECVD can better bridge the vibrational spectrum at the semiconductor/ dielectric interface against substrate roughness. After modification, the interfacial thermal resistance of CVD- $-\mathrm{WSe}_{2}$ on $\mathrm{SiO}_{2} / \mathrm{Si}$ decreases by $4.55 \times 10^{-8} \mathrm{~m}^{2} \mathrm{~K} \mathrm{~W}^{-1}$ to a value smaller than $4.2 \times$ $10^{-8} \mathrm{~m}^{2} \mathrm{~K} \mathrm{~W}^{-1}$, indicating an improved thermal dissipation at the dielectric interface.

\section{Results}

Growth of 2D-BN by ne-PECVD. The PECVD setup is shown in Fig. 1a, which is composed of a 2 -inch quartz tube mounted inside two tubular furnaces and a radiofrequency $(13.56 \mathrm{MHz})$ plasma generator between them. Solid ammonia borane was placed in the center of the tubular furnace (T1) upstream, and then was evaporated and diffused into the zone downstream by an $\mathrm{Ar} / \mathrm{H}_{2}(100 \mathrm{sccm} / 10 \mathrm{sccm})$ carrier gas when the temperature of $T 1$ rose to $110^{\circ} \mathrm{C}$. In the experiment, to obtain a steady precursor supply, ammonia borane was placed in a small quartz tube with one end sealed. 2D-BN films (Fig. 1b) were grown on $\mathrm{SiO}_{2} / \mathrm{Si}$ at $500{ }^{\circ} \mathrm{C}$ in $30 \mathrm{~W}$ plasma (860 mTorr) for $30,40,50$, and $60 \mathrm{~min}$ in the center of the tubular furnace (T2) downstream. Figure $1 \mathrm{c}, \mathrm{d}$ 
a

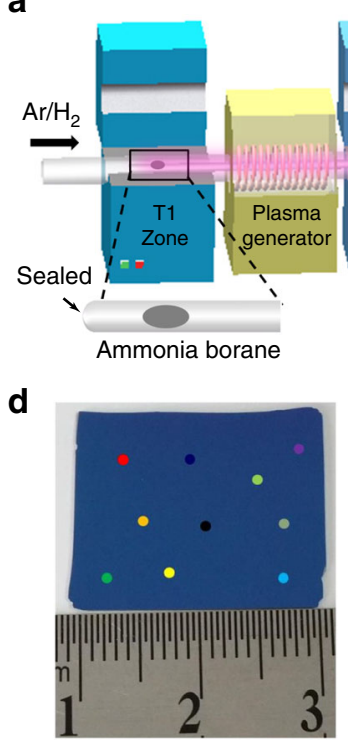

e
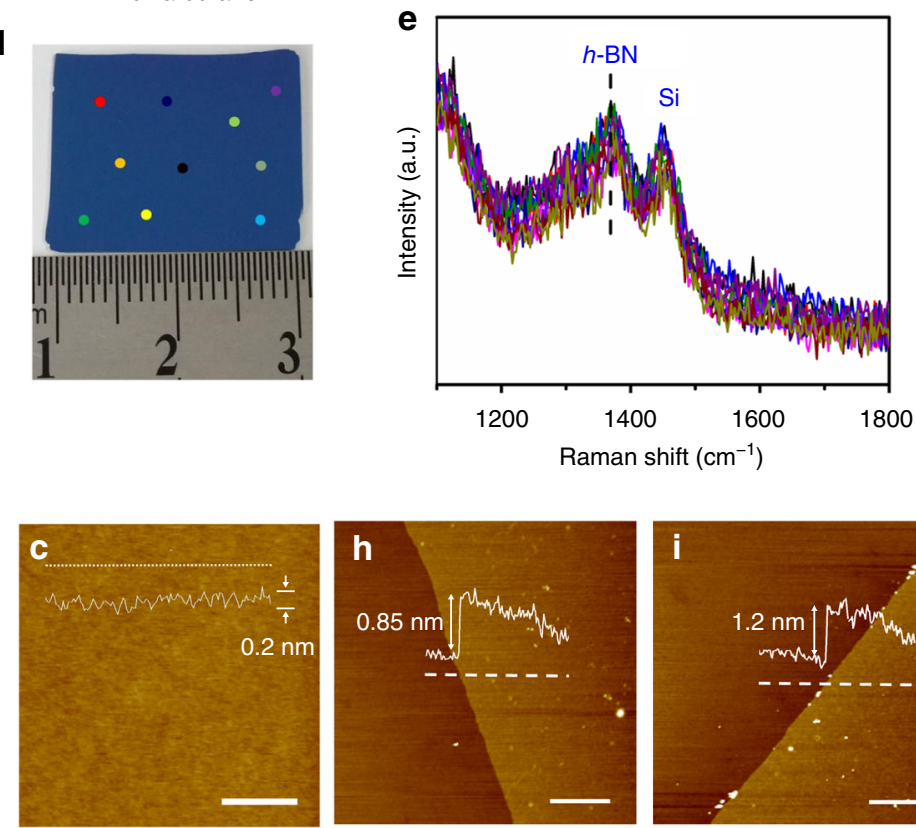

b

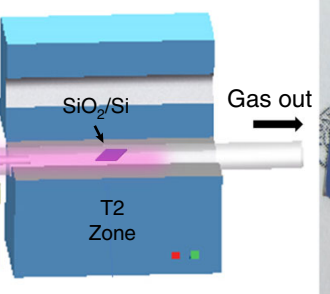

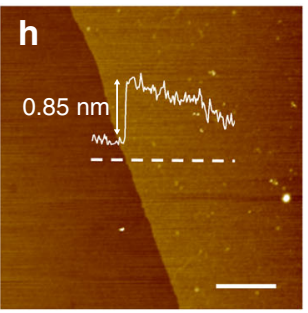

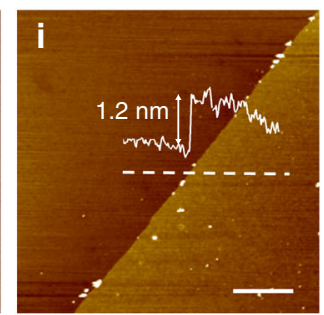

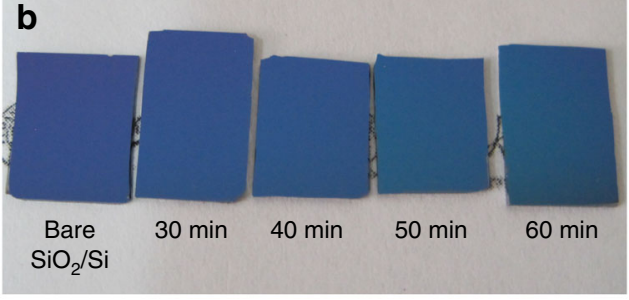
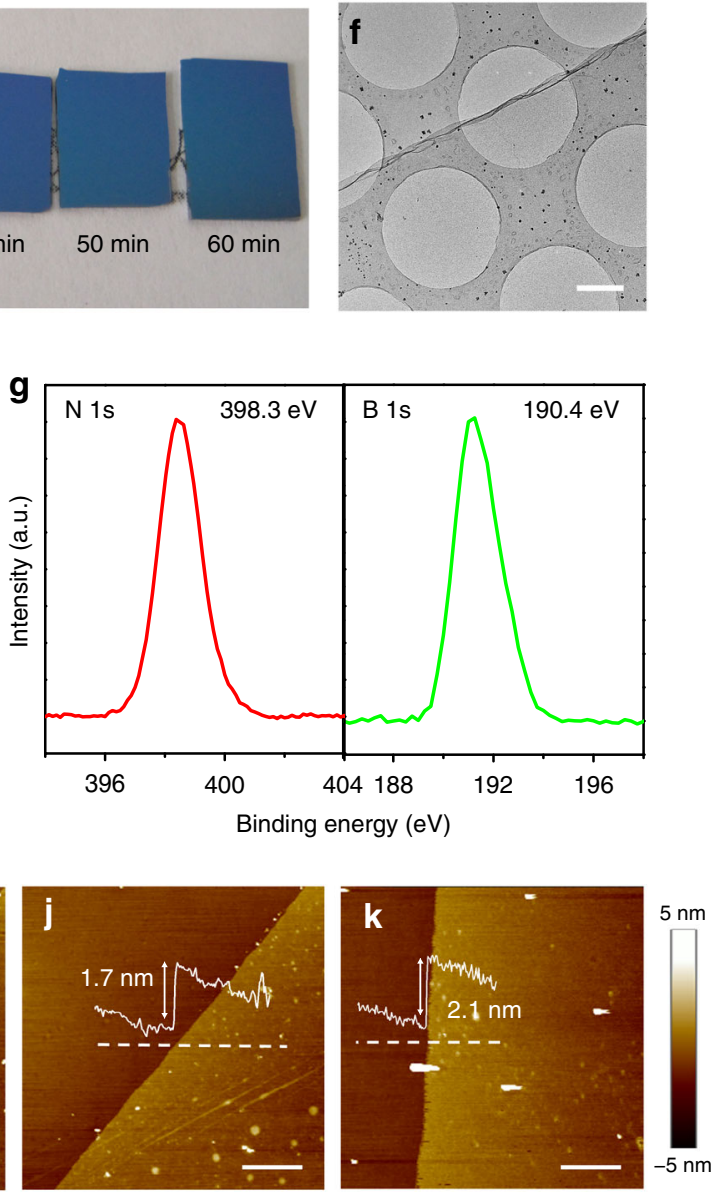

Fig. 1 Growth of two-dimensional hexagonal-boron nitride (2D-BN) by near-equilibrium plasma-enhanced chemical vapor deposition (PECVD). a Schematic illustration of the PECVD system. $\mathbf{b}$ Optical image of bare $\mathrm{SiO}_{2} / \mathrm{Si}, 2 \mathrm{D}-\mathrm{BN}$ grown on $\mathrm{SiO}_{2} / \mathrm{Si}$ after 30, 40, 50, and 60 min growth, respectively. c Atomic force microscope (AFM) and $\mathbf{d}$ optical image of 2D-BN grown on $\mathrm{SiO}_{2} / \mathrm{Si}$ after 30 min growth. e Raman spectra collected from the dots in d. $\mathbf{f}$ Transmission electron microscope (TEM) image of a 2D-BN transferred onto a TEM grid. $\mathbf{g}$ X-ray photoelectron spectroscopy N1s and B1s spectra of $2 \mathrm{D}-\mathrm{BN}$ grown on $\mathrm{SiO}_{2} / \mathrm{Si}$. h-k AFM images of $2 \mathrm{D}-\mathrm{BN}$ transferred to other $\mathrm{SiO}_{2} / \mathrm{Si}$. The growth time is 30, 40, 50 , and 60 min, respectively. The scale bars are $500 \mathrm{~nm}$ in $\mathbf{c}, 1 \mu \mathrm{m}$ in $\mathbf{f}$, and $2 \mu \mathrm{m}$ in $\mathbf{h}-\mathbf{k}$

and Supplementary Fig. 1 show the atomic force microscope (AFM), optical, and scanning electron microscope (SEM) images of the as-grown $2 \mathrm{D}-\mathrm{BN}$ (30 $\mathrm{min}$ ) on $\mathrm{SiO}_{2} / \mathrm{Si}$, respectively. The sample has a homogeneous color contrast and an ultra-smooth surface with roughness (around $0.2 \mathrm{~nm}$ ) similar or even lower than that of bare $\mathrm{SiO}_{2} / \mathrm{Si}$ (Supplementary Fig. 2). Raman spectra (Fig. 1e) are collected from different locations of the sample, all of which have a homogeneous peak at $\sim 1369 \mathrm{~cm}^{-1}$, corresponding to the $E^{2 \mathrm{~g}}$ phonon vibration of $h$ - $\mathrm{BN}$, indicating high uniformity of the as-grown film. The peak at $\sim 1450 \mathrm{~cm}^{-1}$ is assigned to the third-order transverse optical phonon mode of $\mathrm{Si}$ of $\mathrm{SiO}_{2} / \mathrm{Si}$ substrate ${ }^{29}$. The $E^{2 \mathrm{~g}}$ band is located at a similar position to that of CVD 2D-BN (Supplementary Fig. 3), while the full width at half maxima (FWHM, $\sim 49 \mathrm{~cm}^{-1}$ ) of the peak is larger than that $\left(\sim 24 \mathrm{~cm}^{-1}\right)$ of CVD 2D-BN, revealing the poly-crystalline nature of the as-grown film with smaller grain size. After transferring the film to a carbon-copper grid, transmission electron microscope (TEM) image (Fig. 1f) shows a clean, continuous, uniform membrane-like structure. Cross-section TEM images (Supplementary Fig. 4) reveal layered crystalline structures, indicating the $2 \mathrm{D}$ nature of the material. The diffraction spot rings in the selected area electron diffraction (SAED) patterns (Supplementary Fig. 5a, 5b) indicate the poly-crystalline nature of the $2 \mathrm{D}-\mathrm{BN}$. With smaller electron beam spot size, six-fold symmetric diffraction spots (Supplementary Fig. 5c, 5d) can be observed, showing that the sample is composed by small crystalline $h$-BN domains. Energy-dispersive spectroscopy (EDS) collected from the membrane (Supplementary Fig. 6) exhibits B, N element peaks without any other peaks except $\mathrm{C}, \mathrm{Cu}$, and $\mathrm{O}$ (from carboncopper grid), indicating the high sample purity. X-ray photoelectron spectroscopy (XPS, Fig. 1g) reveals an almost equal composition of B and N elements (1:1.12). Symmetrical B $1 s$ and $\mathrm{N} 1 s$ peaks are located at 190.4 and $398.3 \mathrm{eV}$, respectively, indicating that the as-grown sample is predominantly composed of $\mathrm{B}-\mathrm{N}$ bonds with $s p^{2}$ hybridization ${ }^{31}$. To measure the thickness, the as-grown samples with continuous areas up to several square centimeters are transferred to another $\mathrm{SiO}_{2} / \mathrm{Si}$ substrate using poly-methyl-methacrylate (PMMA). The thicknesses (Fig. 1h-k, Supplementary Fig. 7) measured from the boundaries between the sample and $\mathrm{SiO}_{2} / \mathrm{Si}$ are $0.85 \mathrm{~nm}$ (30 min), $1.2 \mathrm{~nm} \mathrm{(40} \mathrm{min),}$ $1.6 \mathrm{~nm}$ (50 $\mathrm{min})$, and $2.1 \mathrm{~nm}$ (60 min), which correspond to 1, 2, 3, and 4 atomic layers of $2 \mathrm{D}-\mathrm{BN}$ excluding the roughness of $\mathrm{SiO}_{2}$ / $\mathrm{Si}^{30}$. The thickness shows a good correlation with the growth time (Supplementary Fig. 8), in consistence with the cross-section TEM results (Supplementary Fig. 4). Therefore, large-area uniform 2D$\mathrm{BN}$ films are grown on $\mathrm{SiO}_{2} / \mathrm{Si}$ with controllable thickness from monolayer to multilayers (Supplementary Figs 4, 9).

The samples are transferred to highly oriented pyrolytic graphite (HOPG) for scanning tunneling microscopy (STM) studies. The grain size is measured in the range of $20 \mathrm{~nm}$ to 

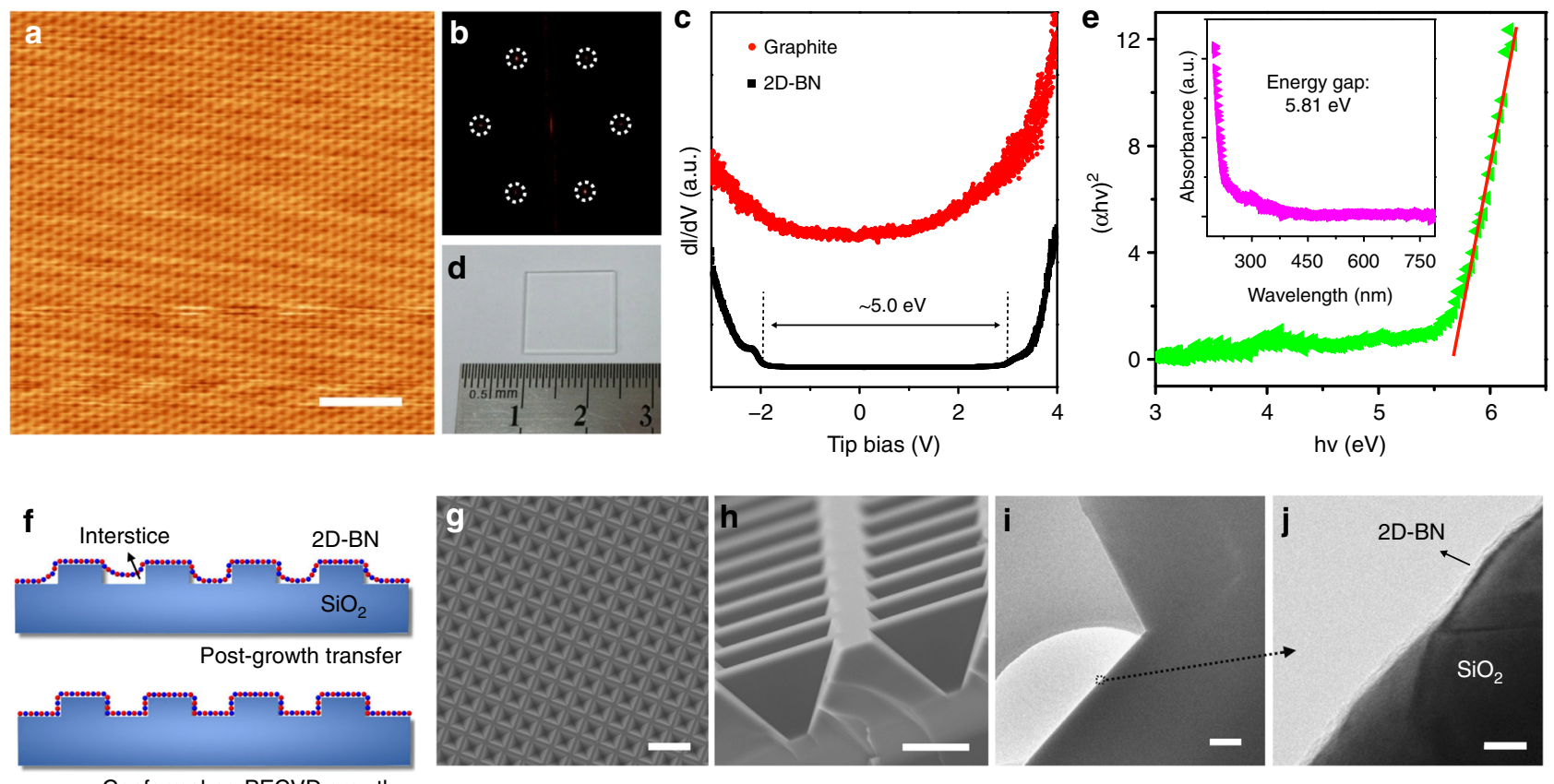

Conformal ne-PECVD growth

Fig. 2 Characterization of two-dimensional hexagonal-boron nitride (2D-BN). a Scanning tunneling microscopy image $\left(V_{\text {Tip }}=-0.5 \mathrm{~V}\right)$ and $\mathbf{b}$ fast Fourier transform (FFT) image of 2D-BN on highly oriented pyrolytic graphite (HOPG). The dashed circles highlight the points of the FFT pattern. c Scanning tunneling spectroscopy spectra collected from 2D-BN and HOPG (set point: $V_{\text {Tip }}=3.0 \mathrm{~V}, I_{\text {Tip }}=48 \mathrm{pA}$ ). $\mathbf{d}$ Optical image and e Tauc plot (inset: ultraviolet spectrum) of 2D-BN grown on quartz. $\mathbf{f}$ Schematic illustration, $\mathbf{g}$ top view scanning electron microscope (SEM), $\mathbf{h}$ side view SEM, and $\mathbf{i}$ cross-section transmission electron microscope (TEM) image of 2D-BN grown by near-equilibrium plasma-enhanced chemical vapor deposition (ne-PECVD) on $\mathrm{SiO}_{2} / \mathrm{Si}$ with three-dimensional structures. $\mathbf{j}$ The higher magnified TEM image of the areas indicated in $\mathbf{i}$ by a dashed frame. The scale bars are $2 \mathrm{~nm}$ in $\mathbf{a}, 10 \mu \mathrm{m}$ in $\mathbf{g}, 2 \mu \mathrm{m}$ in $\mathbf{h}, 200 \mathrm{~nm}$ in $\mathbf{i}$, and $5 \mathrm{~nm}$ in $\mathbf{g}$

more than $200 \mathrm{~nm}$ (Supplementary Fig. 10). Magnified lowtemperature STM (LT-STM) image (Fig. 2a) reveals a honeycomb-like crystalline structure with a nearly atomically clean surface, while the fast Fourier transform (Fig. 2b, Supplementary Fig. 11) image confirms the hexagonal lattice structure. Moiré patterns (Supplementary Fig. 12), which are attributed to the lattice mismatching and rotation of the 2D-BN on HOPG, are observed, indicating high crystallinity of the $2 \mathrm{D}$ $\mathrm{BN}$ domains. The scanning tunneling spectroscopy (STS, Fig. 2c) curve collected from HOPG is a typical $\mathrm{d} I / \mathrm{d} V$ of graphite with no bandgap, while the density of states of $2 \mathrm{D}-\mathrm{BN}$ is remarkably depressed near the Fermi level with a measured band gap around $5.0 \mathrm{eV}$. Compared with intrinsic 2D-BN $(5.9 \mathrm{eV})$, the reduced bandgap is attributed to the weak interaction and the screening from the HOPG substrate ${ }^{36,37}$. The bandgap can also be measured by ultraviolet-visible (UV-vis) absorption spectroscopy. UV-vis spectrum (Fig. 2e) of the 2D-BN grown on quartz (Fig. 2d) exhibits zero absorbance in the visible-light region and a sharp peak at $\sim 200 \mathrm{~nm}$, consistent with the results reported previously ${ }^{27}$. The optical energy gap is calculated by Tauc's equation: $\alpha h v=A\left(h v-E_{\mathrm{g}}\right)^{1 / 2}$, where $\alpha$ is the optical absorption coefficient, $h v$ is the energy of incident photon, $A$ is the proportionality constant, and $E_{\mathrm{g}}$ is energy gap ${ }^{27}$. The $(\alpha h v)^{2}$ vs. $h v$ curve acquired from the sample is shown in Fig. 2e, and the calculated optical energy gap is $5.81 \mathrm{eV}$, which is larger than that of bulk $h$-BN and close to intrinsic $2 \mathrm{D}-\mathrm{BN}^{27}$.

To confirm the conformal growth of $2 \mathrm{D}-\mathrm{BN}, \mathrm{SiO}_{2} / \mathrm{Si}$ with $3 \mathrm{D}$ structures (Fig. 2f) were used as the growth substrate. After nePECVD, XPS spectra (Supplementary Fig. 13) indicate the growth of 2D-BN, while SEM images (Fig. 2g, h, Supplementary Fig. 14) show a clean 3D surface without any bubbles, wrinkles, or incompact contacts, which normally exist in the post-growth transfer CVD samples (Supplementary Fig. 15). The 3D structures were cut and transferred to a copper grad. Crosssection TEM images (Fig. 2i, j) show a closely contacted layer of $2 \mathrm{D}-\mathrm{BN}$ on the $3 \mathrm{D}$ surface, indicating the conformal growth and the potential of ne-PECVD in modifying $3 \mathrm{D}$ dielectric interface for devices with $3 \mathrm{D}$ configuration. Besides $\mathrm{SiO}_{2} / \mathrm{Si}$, substrates like sapphire, silicon, quartz (Supplementary Fig. 16) can also be used in ne-PECVD, and the growth temperature on $\mathrm{SiO}_{2} / \mathrm{Si}$ can decrease to as low as $300^{\circ} \mathrm{C}$ (Supplementary Fig. 17), hundreds of degrees lower than that reported previously ${ }^{27-32}$.

Near-equilibrium growth mechanism. In the growth, ammonia borane is evaporated $\left(\mathrm{H}_{2}\right.$, monomeric aminoborane, borazine also exist owing to thermal decomposition) ${ }^{38}$, and then decomposed into boron and nitrogen species (radicals, ions, and atoms) by the plasma. These highly reactive species overcome the large threshold barrier required, leading to catalyst-free growth of $\mathrm{BN}$ materials directly on the inert surface at low temperature. However, these species are inclined to form structural defects on edges, which prevent the crystal growth of $2 \mathrm{D}-\mathrm{BN}$. Some literatures have demonstrated the etching of $\mathrm{BN}$ materials by $\mathrm{H}_{2}, \mathrm{Ar}, \mathrm{O}_{2}$, or $\mathrm{H}_{2} /$ Ar plasma ${ }^{39-41}$, thus a competition process of etching and nucleation/deposition exists in the PECVD process ${ }^{42}$, however the $2 \mathrm{D}-\mathrm{BN}$ lattice is energetically highly stable. Experiments show no obvious etching of 2D-BN in $\mathrm{H}_{2} / \mathrm{Ar}$ plasma even after $60 \mathrm{~min}$ treatment (Supplementary Fig. 18). Thus, in normal cases, the nucleation/deposition dominates, and disordered or amorphous BN films are grown in a non-equilibrium state as shown in Supplementary Fig. 19, 20 33-35. Nevertheless, the literature and first-principle calculation (Supplementary Note 1) show that the edge defect has a higher energy ${ }^{43}$, compared with pristine $h$-BN lattice and $\mathrm{H}$-passivated edges. The energy increases by 7.458 and $9.526 \mathrm{eV}$, when a $\mathrm{B}_{3} \mathrm{~N}_{2}$ or $\mathrm{B}_{2} \mathrm{~N}_{3}$ pentagonal defect forms on 
a

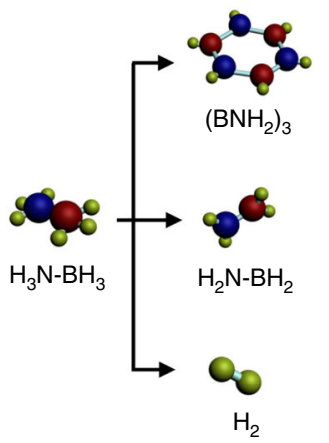

Nitrogen
Boron
Hydrogen

\section{$\mathrm{H}_{2} /$ Ar plasma}
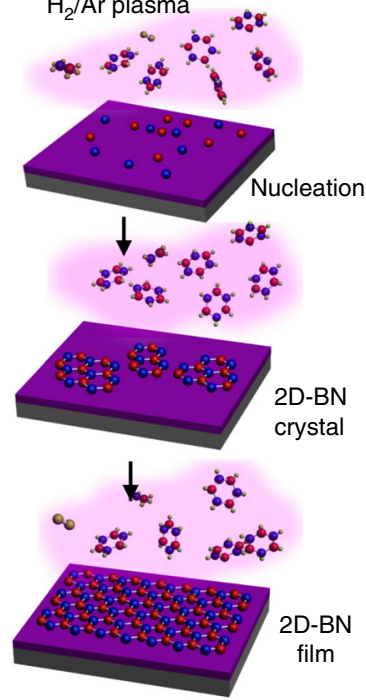
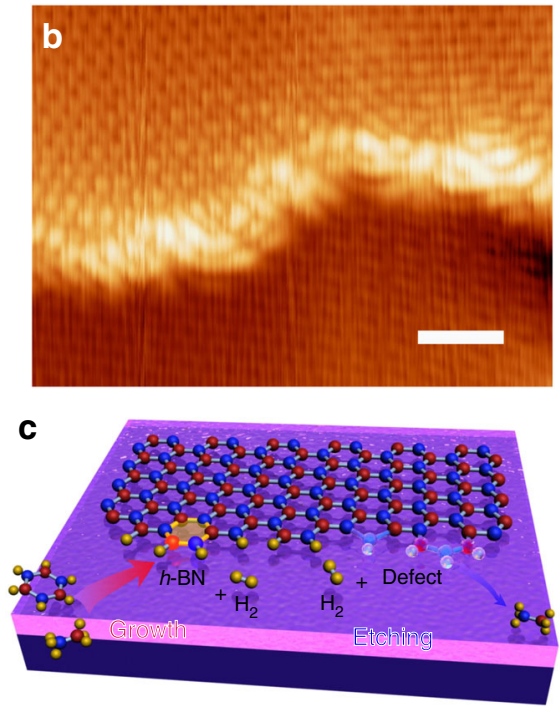

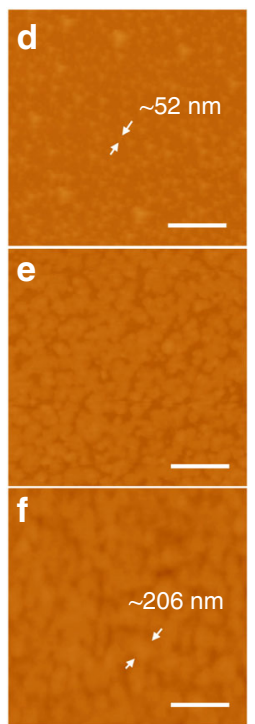

Fig. 3 Growth mechanism of near-equilibrium plasma-enhanced chemical vapor deposition (ne-PECVD). a Schematic illustration of the growth process of two-dimensional hexagonal-boron nitride $(2 \mathrm{D}-\mathrm{BN})$ on $\mathrm{SiO}_{2} / \mathrm{Si}$. b Scanning tunneling microscopy image of a $2 \mathrm{D}-\mathrm{BN}$ edge $\left(V_{\text {Tip }}=-0.5 \mathrm{~V}\right)$. c $\mathrm{Schematic}$ illustration of the competition process of 2D-BN growth and etching in ne-PECVD. $\mathbf{d}-\mathbf{f}$ Atomic force microscope images of the 2D-BN domains grown on $\mathrm{SiO} 2 / \mathrm{Si}$ by ne-PECVD for $\mathbf{d} 8 \mathrm{~min}$, e $15 \mathrm{~min}$, and $\mathbf{f} 20 \mathrm{~min}$. The scale bars are $1 \mathrm{~nm}$ in $\mathbf{b}$ and $500 \mathrm{~nm}$ in $\mathbf{d}-\mathbf{f}$

H-passivated armchair edges (Supplementary Fig. 21). Thus, the etching tends to occur at the edge defects. Owing to the low etching rate, a slow and steady precursor feeding is required to establish a reversible competition between the nucleation/growth and the etching. Therefore, controlled experiments (Supplementary Fig. 22, 23) show that a slow and steady precursor feeding is pivotal for the $2 \mathrm{D}-\mathrm{BN}$ growth, which requires placing the precursor in a small quartz tube with one end sealed and maintains at a temperature (T1) below $115^{\circ} \mathrm{C}$. In such a near-equilibrium state (Supplementary Note 2), moderate etching by the $\mathrm{H}_{2} / \mathrm{Ar}$ plasma removes defects generated on the edges and keeps the edges atomically smooth (Fig. 3b) and active during the whole PECVD process, resulting in efficient crystal growth of 2D-BN directly on the inert surface without any catalyst (Fig. 3c). The 2D-BN crystals nucleate and the grain sizes gradually increase up to more than $200 \mathrm{~nm}$ (Fig. 3d-f), and finally a continuous 2D-BN film is obtained on the substrate.

CVD growth of $\mathrm{WSe}_{2}$ on 2D-BN. The benefit of ne-PECVD is that it modifies flat or $3 \mathrm{D}$ substrates with an atomically clean conformal van-der-Waals dielectric surface, which can be directly used in electrical devices. We grew $2 \mathrm{D} \mathrm{WSe}_{2}$ crystals (CVD$\mathrm{WSe}_{2}$ ) on $2 \mathrm{D}-\mathrm{BN} / \mathrm{SiO}_{2} / \mathrm{Si}$ by $\mathrm{CVD}$ for back-gated FETs. In the growth, a quartz boat with $450 \mathrm{mg}$ Se powder was placed upstream in the furnace, while $130 \mathrm{mg} \mathrm{WO}_{3}$ powder was placed downstream (Supplementary Fig. 24). The substrates were placed on the top of $\mathrm{WO}_{3}$ with the surface facing down. The upstream and downstream zones were gradually heated from room temperature to 300 and $920^{\circ} \mathrm{C}$ in $300 \mathrm{sccm}$ pure Ar within $30 \mathrm{~min}$. And then, a mixture of $85 \mathrm{sccm} \mathrm{Ar}$ and $15 \mathrm{sccm} \mathrm{H} \mathrm{H}_{2}$ was introduced into the furnace. After $15 \mathrm{~min}$ growth, the furnace was naturally cooled down to $300^{\circ} \mathrm{C}$, and was fast cooled down to room temperature. AFM and optical images (Fig. 4a, Supplementary Fig. 25) show that most of the as-grown CVD-WSe crystals have a triangular or hexagonal shape with a size of about $30-200 \mu \mathrm{m}$ and a height of about $1.2 \mathrm{~nm}$. The high-resolution TEM image and the hexagonal arrangement of the SAED pattern (Fig. 4b, c) show the CVD-WSe ${ }_{2}$ sample is well crystallized with the measured lattice spacing of $0.28 \mathrm{~nm}$, in consistent with the
(100) plane spacing of $2 \mathrm{H}-\mathrm{WSe} \mathrm{S}_{2}$. In Raman spectrum (Fig. $4 \mathrm{~d}$ ), an intrinsic $E_{2 \mathrm{~g}}^{1}$ band at $248 \mathrm{~cm}^{-1}$ and the absence of the $B^{1}{ }_{2 \mathrm{~g}}$ mode at $307 \mathrm{~cm}^{-1}$ indicate the monolayer nature of the CVD$\mathrm{WSe}_{2}{ }^{7,25,44}$. The photoluminescence (PL) spectrum (Fig. 4e) exhibits strong emission at $768 \mathrm{~nm}$, corresponding to the direct bandgap of monolayer $\mathrm{WSe}_{2} 7,8,24,25$. The highly crystalline structure (Fig. $4 \mathrm{~b}$ ), as well as the narrow $E_{2 \mathrm{~g}}^{1}$ Raman peak (a FWHM of $5.7 \mathrm{~cm}^{-1}$ ) and the sharp PL emission (a FWHM of 49 $\mathrm{meV}$ ) without the defect emission at $1.54 \mathrm{eV}^{7,8,25,44}$, indicate high quality of the CVD-WSe $\mathrm{W}_{2}$ samples grown on the ne-PECVD 2D-BN.

Enhanced mobility of $\mathrm{WSe}_{2}$ on $2 \mathrm{D}-\mathrm{BN}$. After CVD growth, the back-gated FETs were directly fabricated by using $2 \mathrm{D}-\mathrm{BN} / \mathrm{SiO}_{2} / \mathrm{Si}$ as gate dielectric and back gate, using $\mathrm{CVD}-\mathrm{WSe}_{2}$ as the conducting channel (Fig. 5). All devices were current-annealed or thermal-annealed, and then were measured under ambient conditions. As a comparison, CVD-WSe ${ }_{2}$ FETs were also fabricated using bare $\mathrm{SiO}_{2} / \mathrm{Si}$. Drain-source current $\left(I_{\mathrm{ds}}\right)$ vs. drain-source voltage $\left(V_{\mathrm{ds}}\right)$ (output curve, Fig. $\left.5 \mathrm{~b}\right)$ and $I_{\mathrm{ds}}$ vs. gate voltage $\left(V_{\mathrm{g}}\right)$ (transfer curve, $V_{\mathrm{ds}}$ at $-2 \mathrm{~V}$, Fig. $5 \mathrm{c}$ ) show a typical $p$-type characteristic with an on/off ratio up to $1 \times 10^{8}$ and $1 \times 10^{7}$ for CVD-WSe ${ }_{2}$ FETs on $2 \mathrm{D}-\mathrm{BN} / \mathrm{SiO}_{2} / \mathrm{Si}$ and on bare $\mathrm{SiO}_{2} / \mathrm{Si}$ substrates, respectively, when the gate voltage sweeps from -80 to $80 \mathrm{~V}$. The mobility is calculated (Supplementary Note 3, Supplementary Fig. 26) by the equation ${ }^{3-5}$ :

$$
\mu=\left(\frac{L}{W C_{\mathrm{i}} V_{\mathrm{ds}}}\right)\left(\frac{\Delta I_{\mathrm{ds}}}{\Delta V_{\mathrm{g}}}\right)
$$

where $C_{\mathrm{i}}$ is the dielectric capacitance, $W$ is the channel width, $L$ is the channel length, and $\left(\Delta I_{\mathrm{ds}} / \Delta V_{\mathrm{g}}\right)$ is the slope of the transfer curves in the linear regime. The calculated mobility of CVD$\mathrm{WSe}_{2}$ on $2 \mathrm{D}-\mathrm{BN} / \mathrm{SiO}_{2} / \mathrm{Si}$ is around $56-121 \mathrm{~cm}^{2} \mathrm{~V}^{-1} \mathrm{~s}^{-1}$, which is higher than that of CVD-WSe 2 grown on bare $\mathrm{SiO}_{2} / \mathrm{Si}$ (Fig. $5 \mathrm{e}$, $\left.2-21 \mathrm{~cm}^{2} \mathrm{~V}^{-1} \mathrm{~s}^{-1}\right)$ and the room-temperature mobility (10-30 $\mathrm{cm}^{2} \mathrm{~V}^{-1} \mathrm{~s}^{-1}$ ) of monolayer $\mathrm{WSe}_{2}$ on bare $\mathrm{SiO}_{2} / \mathrm{Si}$ or $\mathrm{Al}_{2} \mathrm{O}_{3}$ reported previously ${ }^{3-5}$. The increased mobility is in good agreement with that of $2 \mathrm{D}$ semiconductor devices on peel-off or CVD 

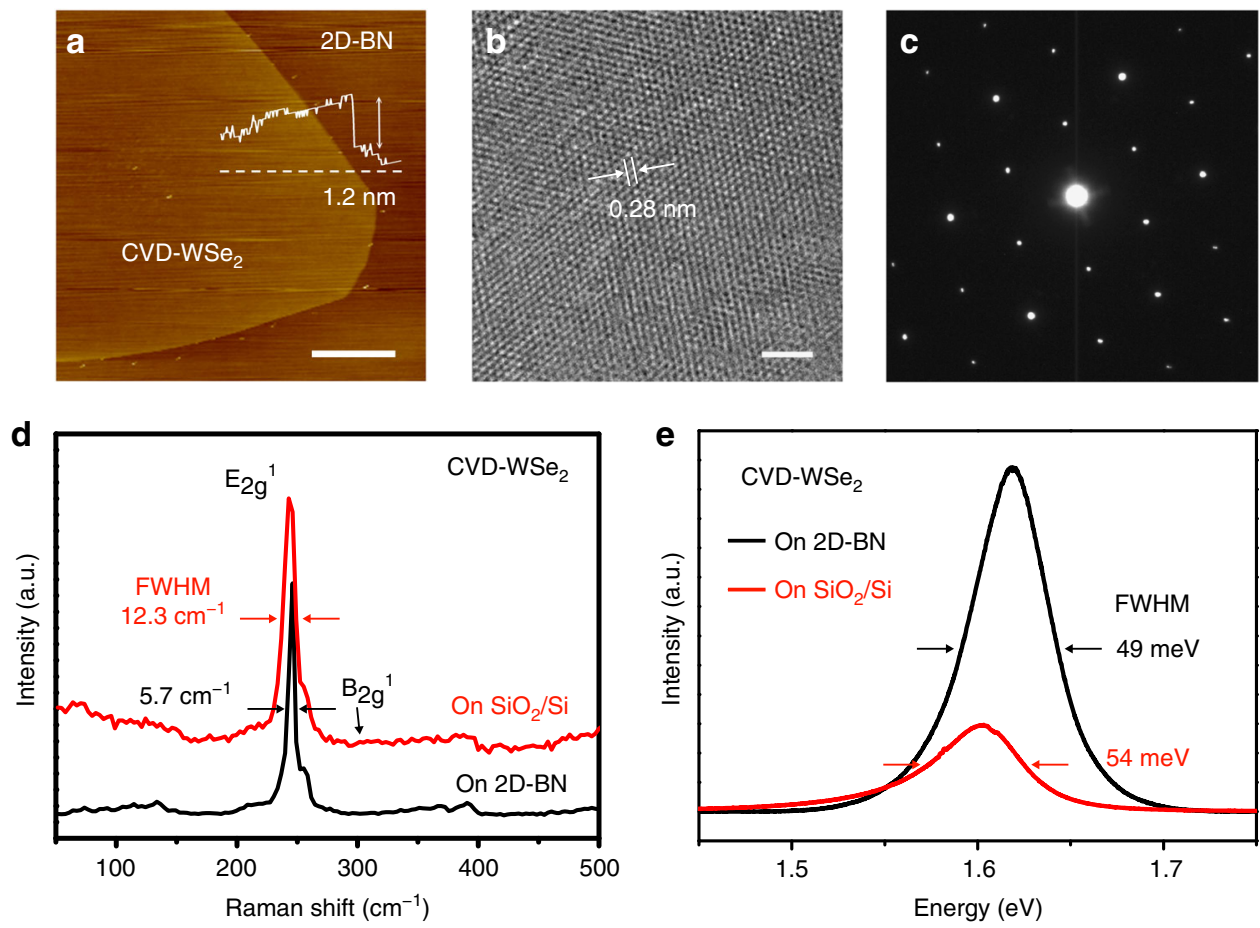

Fig. 4 Direct growth of CVD-WSe $e_{2}$ on two-dimensional hexagonal-boron nitride (2D-BN). a Atomic force microscope image of a CVD-WSe 2 crystal grown on 2D-BN. b High-resolution transmission electron microscope image and $\mathbf{c}$ selected area electron diffraction patterns of a CVD-WSe 2 crystal. The (100) plane space is $0.28 \mathrm{~nm}$. d Raman spectra of a CVD-WSe $e_{2}$ crystal grown on $2 \mathrm{D}-\mathrm{BN}$ or on bare $\mathrm{SiO}_{2} / \mathrm{Si}$. The full width at half maxima (FWHM) of the $E_{2 \mathrm{~g}}$ band is 5.7 and $12.3 \mathrm{~cm}^{-1}$, respectively. e Photoluminescence spectra of the CVD-WSe 2 grown on 2D-BN or on bare $\mathrm{SiO}_{2} / \mathrm{Si}$. The FWHM of the peak is 49 and $54 \mathrm{meV}$, respectively. The scale bars are $5 \mu \mathrm{m}$ in $\mathbf{a}$ and $2 \mathrm{~nm}$ in $\mathbf{b}$

$2 \mathrm{D}-\mathrm{BN}$ reported previously $9,12-15$, indicating the high quality of the $2 \mathrm{D}-\mathrm{BN}$ produced by ne-PECVD.

There are several reasons for the increased mobility of CVD$\mathrm{WSe}_{2}$ on ne-PECVD 2D-BN. The main reason is the smooth vander-Waals conformal surface of the 2D-BN, as shown in STM image (Fig. 2a). Atomically thin 2D materials have a large surface-to-volume ratio, thus the carrier conduction is significantly influenced by the dielectric interface. At the interface, the modification with $2 \mathrm{D}-\mathrm{BN}$ avoids surface roughness, dangling bonds, surface charge impurities or traps, which normally exist on bare $\mathrm{SiO}_{2} / \mathrm{Si}^{7-15}$, and decreases charge carrier scattering. As a result, the $2 \mathrm{D}-\mathrm{BN}$ remarkably improves the carrier mobility of $2 \mathrm{D}$ or organic materials ${ }^{7-15,25}$. For instance, Kim et al. reported that $\mathrm{MoS}_{2}$ mobility increased from 10 to $42 \mathrm{~cm}^{2} \mathrm{~V}^{-1} \mathrm{~s}^{-1}$ by introducing highly crystalline CVD $h$-BN between $\mathrm{MoS}_{2}$ and $\mathrm{SiO}_{2} / \mathrm{Si}^{25}$. In the case of CVD-WSe ${ }_{2}$ on ne-PECVD 2D-BN (Fig. 4e), the narrow symmetrical PL peak originated from the neutral exciton emission is observed $7,24,25$, while the PL of CVD-WSe $\mathrm{Wn}_{2}$ on $\mathrm{SiO}_{2} / \mathrm{Si}$ is weaker with a red shift $(17 \mathrm{meV})$ and unsymmetrical profile, corresponding to a charged exciton (trion) emission $7,24,25$. The PL spectra indicate that the ne-PECVD 2D-BN is more chargeneutral, which strongly suppresses and screens out the influence of charge impurities existing on bare $\mathrm{SiO}_{2} / \mathrm{Si}^{7,24,25}$. Moreover, the inert 2D-BN surface has low charge trap density. Joo et al. observed the reduction of interfacial traps density by 100 times compared with that on $\mathrm{SiO}_{2} / \mathrm{Si}^{11}$. To clarify trap states on $2 \mathrm{D}-\mathrm{BN}$, we investigated the hysteresis in the transfer characteristics of $\mathrm{CVD} \mathrm{WSe}_{2}$ FETs (Fig. 5g, h, Supplementary Fig. 27). On bare $\mathrm{SiO}_{2} / \mathrm{Si}$ or disordered PECVD BN film, an obvious hysteresis exists, while it becomes much smaller on ne-PECVD 2D-BN. This result reveals a charge trap-free dielectric interface of the nePECVD 2D-BN $10,11,14,15$, thus it avoids accumulation of charge impurities at the interface of $\mathrm{SiO}_{2} / \mathrm{Si}$, which are normally regarded as carrier scattering centers to decrease the mobility $10,11,14,15$.

The other reason is the clean dielectric interface. Moderate etching effect of $\mathrm{Ar} / \mathrm{H}_{2}$ plasma in ne-PECVD removes the surface impurities generated on $2 \mathrm{D}-\mathrm{BN}$, resulting in an atomically clean surface (Fig. 2a). After ne-PECVD, CVD-WSe ${ }_{2}$ crystals are directly grown on $2 \mathrm{D}-\mathrm{BN} / \mathrm{SiO}_{2} / \mathrm{Si}$, avoiding postgrowth transfer. The post-growth transfer normally involves a deposition of polymers and a solution-washing process, thus this process introduces contamination or defects at the interface and causes low quality of interlayer contact $\mathrm{t}^{8,26,45}$, leading to reduction of the device performance ${ }^{7,8,45}$. Control experiments show that the post-growth transferred CVD-WSe $2\left(\mathrm{PT}-\mathrm{WSe}_{2}\right)$ on $2 \mathrm{D}-\mathrm{BN} / \mathrm{SiO}_{2} / \mathrm{Si}$ has an obvious hysteresis in the transfer curve (Supplementary Fig. 27). The mobility (Fig. 5e, f) decreases to $26.3-70.2 \mathrm{~cm}^{2} \mathrm{~V}^{-1} \mathrm{~s}^{-1}$, lower than that $(56-121$ $\mathrm{cm}^{2} \mathrm{~V}^{-1} \mathrm{~s}^{-1}$ ) of the directly grown samples. Therefore, the moderate plasma etching as well as the direct CVD growth, in principle, realizes a clean and smooth interlayer interface between $2 \mathrm{D}-\mathrm{BN}$ and $\mathrm{WSe}_{2}$, compared with the transferred structures, which is one of the key factors to obtain the intrinsic properties of $\mathrm{WSe}_{2}$ or other $2 \mathrm{D}$ materials ${ }^{7,26,46,47}$.

Moreover, the improved sample quality, when using $2 \mathrm{D}-\mathrm{BN}$ as the growth substrate $2,24,48$, should be one of other probable reasons for the increased mobility of CVD-WSe $\mathrm{C}_{2}$ on ne-PECVD 2D-BN. Uchida et al. and Okada et al. show that higher quality of transition metal dichalcogenides (TMDs) such as $\mathrm{WS}_{2}$ can be produced on flat $2 \mathrm{D}-\mathrm{BN}$ without dangling bonds and contaminations compared with the sample grown on $\mathrm{SiO}_{2}$ or postgrowth transferred 2D-BN ${ }^{2,24}$. Similarly, in this work, the FWHM of the Raman $E^{1}{ }_{2 \mathrm{~g}}$ peak (Fig. $4 \mathrm{~d}$ ) and the FWHM of the PL peak (Fig. 4e) decreases from $12.3 \mathrm{~cm}^{-1}$ and $54 \mathrm{meV}$ (grown on $\mathrm{SiO}_{2} /$ $\mathrm{Si}$ ) to $5.7 \mathrm{~cm}^{-1}$ and $49 \mathrm{meV}$ (grown on $2 \mathrm{D}-\mathrm{BN}$ ), respectively, 
a

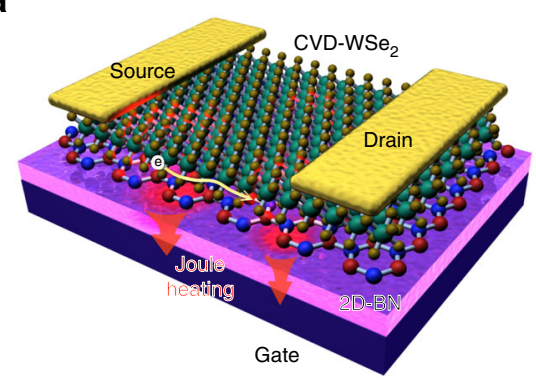

b

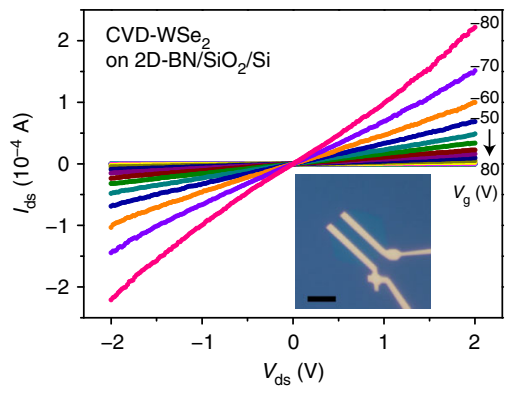

e

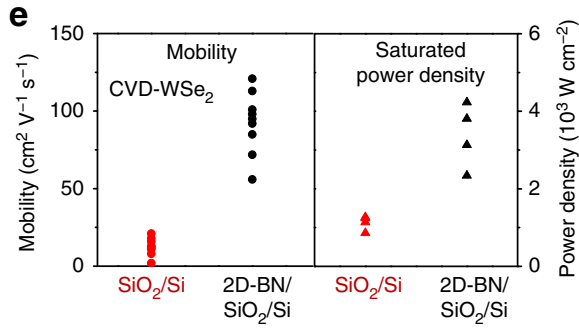

C

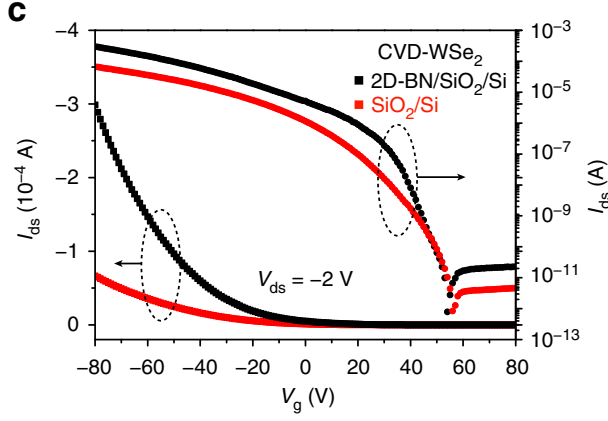

g

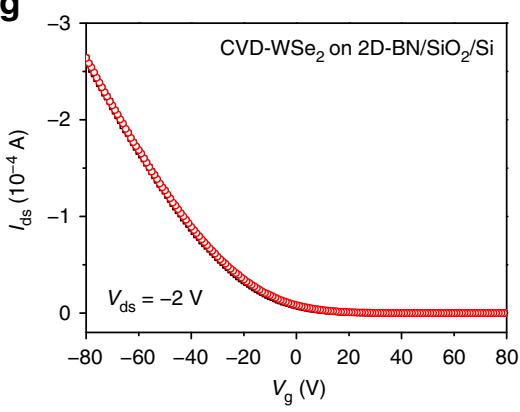

d

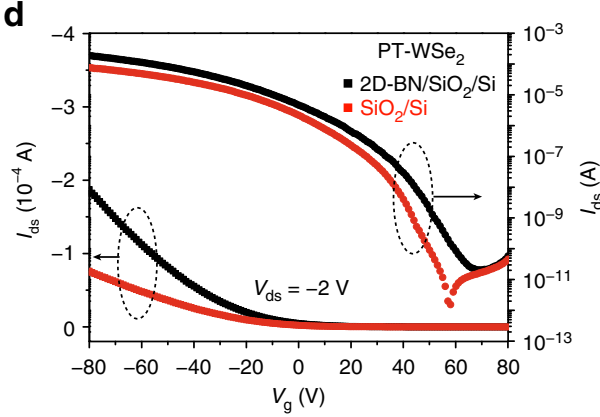

h
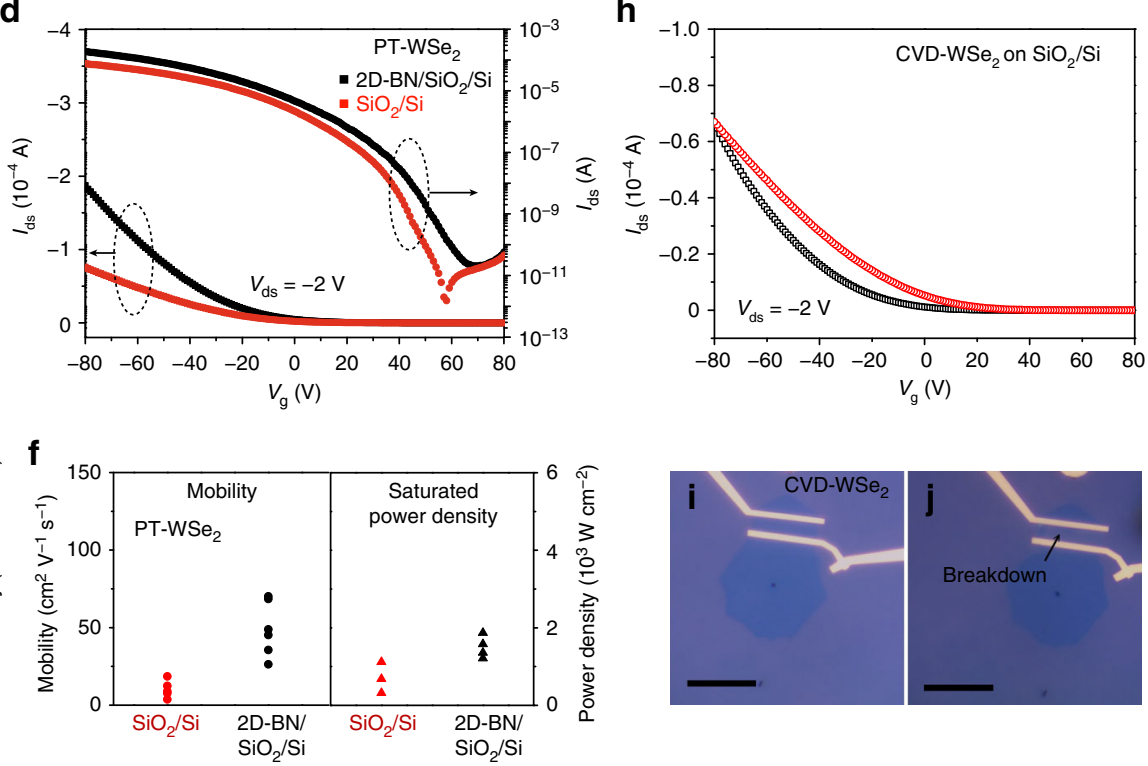

Fig. 5 Two-dimensional hexagonal-boron nitride (2D-BN) as dielectric interfacial material in field-effect transistors (FETs). a Schematic illustration of a CVD-WSe ${ }_{2}$ FET device using 2D-BN as the dielectric interface. b Output curves of the CVD-WSe $\mathrm{FET}_{2}$ on $2 \mathrm{D}-\mathrm{BN} / \mathrm{SiO}_{2} / \mathrm{Si}$. The inset shows the optical image of the device. $\mathbf{c}, \mathbf{d}$ Transfer curves $\left(V_{\mathrm{ds}}=-2 \mathrm{~V}\right)$ of the CVD-WSe $2 \mathrm{FET}$ and a PT-WSe $2 \mathrm{FET}$ on $2 \mathrm{D}-\mathrm{BN} / \mathrm{SiO}_{2} / \mathrm{Si}$ and on bare $\mathrm{SiO} / 2 / \mathrm{Si}$. e, $\mathbf{f} \mathrm{Mobility}$ and saturated power density of the CVD-WSe $\mathrm{FET}_{2}$ and the PT-WSe $\mathrm{FET}_{2}$ on $2 \mathrm{D}-\mathrm{BN} / \mathrm{SiO}_{2} / \mathrm{Si}$ and on bare $\mathrm{SiO}_{2} / \mathrm{Si}$. $\mathbf{g}$, $\mathbf{h} \mathrm{Transfer}$ curve $\left(V_{\mathrm{ds}}=-2 \mathrm{~V}\right)$ of a CVDWSe $\mathrm{FET}_{2}$ on $2 \mathrm{D}-\mathrm{BN} / \mathrm{SiO}_{2} / \mathrm{Si}$ and on $\mathrm{SiO} 2 / \mathrm{Si}$. The black and red curves are obtained when $\mathrm{V}_{\mathrm{g}}$ sweeps from 80 to $-80 \mathrm{~V}$ and from -80 to $80 \mathrm{~V}$, respectively. $\mathbf{i}, \mathbf{j}$ Optical images of a CVD-WSe 2 FET on $2 \mathrm{D}-\mathrm{BN} / \mathrm{SiO}_{2} / \mathrm{Si}$ before and after current breakdown. Scale bars in $\mathbf{b}, \mathbf{i}, \mathbf{j}$ are $20 \mu \mathrm{m}$

indicating that higher crystallinity of the CVD-WSe ${ }_{2}$ is obtained when the growth takes place on ne-PECVD $2 \mathrm{D}-\mathrm{BN}^{2,24,44}$. In order to avoid the difference in sample quality, we grew CVD$\mathrm{WSe}_{2}$ on $\mathrm{SiO}_{2} / \mathrm{Si}$ and then transferred to other substrates (Fig. $5 \mathrm{~d}-\mathrm{f}$ ). Although the mobility of PT-WSe $\mathrm{W}_{2}$ on $2 \mathrm{D}-\mathrm{BN} / \mathrm{SiO}_{2} /$ Si $\left(26.3-70.2 \mathrm{~cm}^{2} \mathrm{~V}^{-1} \mathrm{~s}^{-1}\right)$ is lower than that of CVD-WSe $\mathrm{C}_{2}$ on $2 \mathrm{D}-\mathrm{BN} / \mathrm{SiO}_{2} / \mathrm{Si}$ due to the impurities or defects introduced by the post-growth transfer process $7,26,46,47$, it is still higher than that of PT-WSe 2 on bare $\mathrm{SiO}_{2} / \mathrm{Si}\left(3.8-18.6 \mathrm{~cm}^{2} \mathrm{~V}^{-1} \mathrm{~s}^{-1}\right)$, indicating that the improved $\mathrm{WSe}_{2}$ mobility on $2 \mathrm{D}-\mathrm{BN} / \mathrm{SiO}_{2} / \mathrm{Si}$ mainly originates from the $2 \mathrm{D}-\mathrm{BN}$ layer rather than the sample quality.

Improved thermal dissipation of WSe $\mathrm{W}_{2}$ FETs on 2D-BN. The thermal dissipation is a great challenge for devices or integrated circuits with ultrahigh operating frequency, especially for $\mathrm{WSe}_{2}$ FETs, as the $\mathrm{WSe}_{2}$ is normally regarded as a material with the lowest thermal conductivity ${ }^{6}$. Although much research has demonstrated the $2 \mathrm{D}-\mathrm{BN}$ as an ideal dielectric material for improving the device mobility, its potential application in improving the thermal dissipation of a FET device is usually ignored. We measured the saturated power density of CVD-WSe FETs on different substrates when current breakdown took place (Fig. 5i, j, Supplementary Fig. 28). The saturated power density
(Fig. 5e, f), calculated by the power at the current breakdown divided by the device area, reaches up to $4.23 \times 10^{3}\left(\mathrm{CVD}-\mathrm{WS} \mathrm{S}_{2}\right)$ and $1.87 \times 10^{3} \mathrm{~W} \mathrm{~cm}^{-2}\left(\mathrm{PT}-\mathrm{WSe}_{2}\right)$ on $2 \mathrm{D}-\mathrm{BN} / \mathrm{SiO}_{2} / \mathrm{Si}$, higher than that on bare $\mathrm{SiO}_{2} / \mathrm{Si}$, indicating that the ne-PECVD 2D-BN not only increases the device mobility but also increases device stability with higher saturated power density.

The increased saturated power density is attributed to the improved interfacial thermal dissipation at the dielectric interface with 2D-BN. Different from thermal conductivity, interfacial thermal conductivity is a measure of an interface's conductivity to thermal flow, which exists even at atomically perfect interfaces. Despite the large in-plane thermal conductivity of $2 \mathrm{D}-\mathrm{BN}$, it is atomically thin, the in-plane thermal flow can be ignored, and the interfacial thermal resistance across the dielectric interface dominates the thermal conduction ${ }^{18,49}$, which plays a critical role in the saturated power density of the devices. A scanning thermal microscope (SThM), which operates by scanning a sample solid surface with a sharp temperature-sensing tip, is a powerful tool for imaging sub-micron heat transfer at surface and subsurface levels ${ }^{50}$. When the tip scans on the sample surface by an active and contact mode; 2D-mapping thermal images of $\mathrm{CVD}-\mathrm{WSe} \mathrm{H}_{2} / 2 \mathrm{D}-\mathrm{BN} / \mathrm{SiO}_{2}$ and $\mathrm{CVD}-\mathrm{WSe}{ }_{2} / \mathrm{SiO}_{2}$ (Fig. 6a, b) are obtained by monitoring the temperature changes $(\Delta T)$ of the tip. As a comparison, other TMDs materials (CVD-MoSe 2 , Fig. 6c, d) 

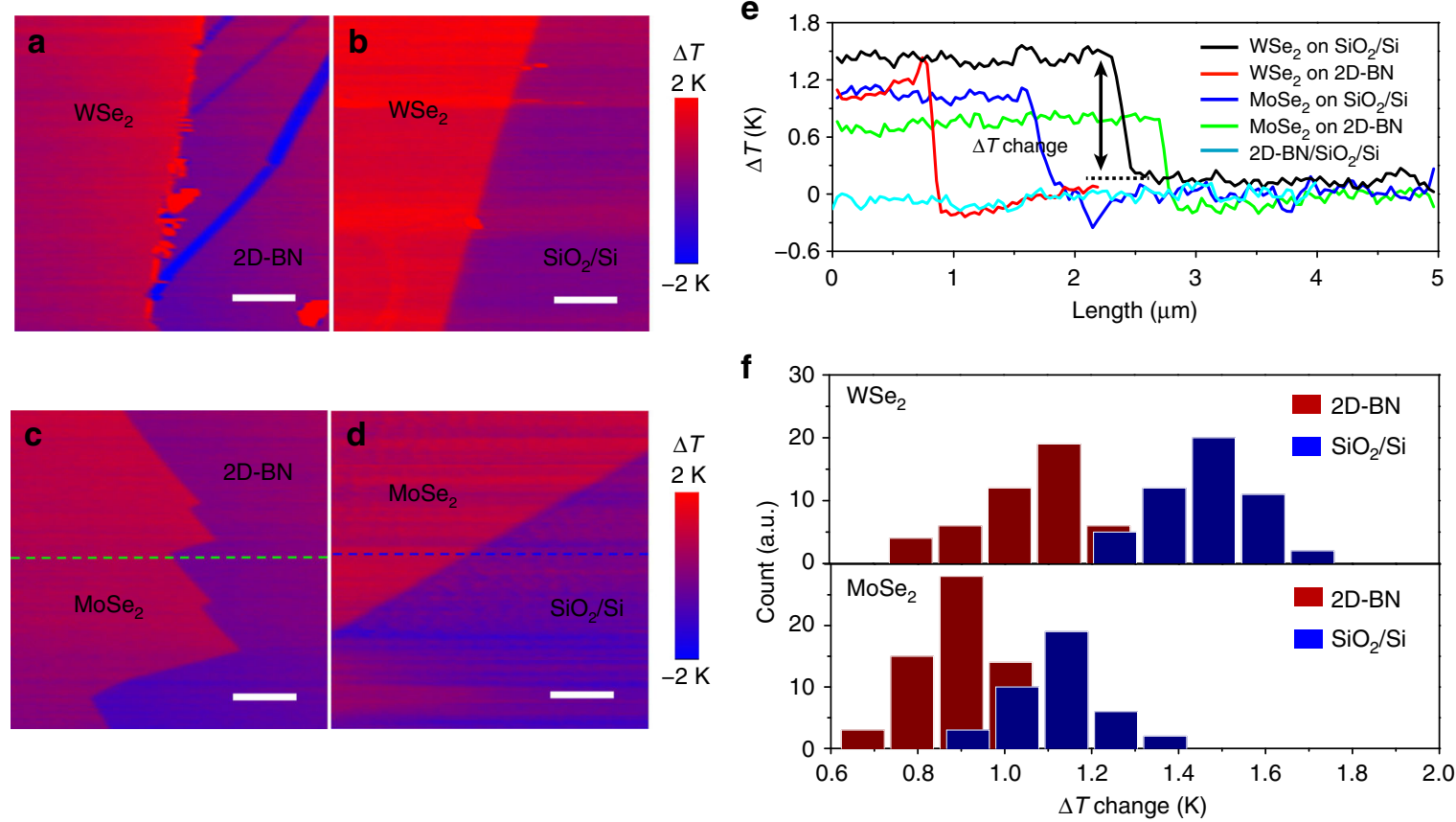

Fig. 6 Scanning thermal microscope (SThM) measurement of the interfacial thermal dissipation. a-d $\mathrm{SThM}$ thermal images of a WSe $\mathrm{H}_{2}$ on $2 \mathrm{D}-\mathrm{BN} / \mathrm{SiO} \mathrm{O}_{2} / \mathrm{Si}_{\text {, }}$ b $\mathrm{WSe}_{2}$ on $\mathrm{SiO}_{2} / \mathrm{Si}$, c $\mathrm{MoSe}_{2}$ on $2 \mathrm{D}-\mathrm{BN} / \mathrm{SiO}_{2} / \mathrm{Si}$, and $\mathbf{d} \mathrm{MoSe}_{2}$ on $\mathrm{SiO}_{2} / \mathrm{Si}$. e The cross-sectional profiles where temperature changes $(\Delta T)$ are recorded across the $2 \mathrm{D}-\mathrm{BN} / \mathrm{SiO}_{2} / \mathrm{Si}$ surface or the $\mathrm{WSe} \mathrm{e}_{2}, \mathrm{MoSe}_{2}$ edges along the dashed lines in a-d. $\mathbf{f}$ The histograms show the $\Delta T$ change across the WSe $e_{2}$ or $\mathrm{MoSe}_{2}$ edge on $2 \mathrm{D}-\mathrm{BN} / \mathrm{SiO}_{2} / \mathrm{Si}$ or $\mathrm{SiO}_{2} / \mathrm{Si}$. Scale bars in $\mathbf{a}-\mathbf{d}$ are $1 \mu \mathrm{m}$

are also measured. No obvious $\Delta T$ change is observed on $2 \mathrm{D}-\mathrm{BN} /$ $\mathrm{SiO}_{2}$, owing to efficient thermal dissipation between the tip and the substrate across the $2 \mathrm{D}-\mathrm{BN}$. Although the sample (CVD$\mathrm{MoSe}_{2}$ or CVD-WSe 2 /2D-BN/SiO${ }_{2}$ has more interfaces compared with the sample $/ \mathrm{SiO}_{2}$, the former has lower $\Delta T$ change (Fig. 6e, f), indicating that the 2D-BN layer helps thermal dissipation from tip to substrate across the sample/dielectric interface (Supplementary Note 4).

To quantify the thermal dissipation, interfacial thermal resistance measurements were carried out by differential $3 \omega$ method (Fig. $7 \mathrm{a}$, b, Supplementary Fig. 29, Supplementary Note 5) ${ }^{18,49}$. Although the channel/2D-BN/SiO 2 contains two interfaces, i.e. the channel/2D$\mathrm{BN}$ interface and the $2 \mathrm{D}-\mathrm{BN} / \mathrm{SiO}_{2}$ interface, while the channel/ $/ \mathrm{SiO}_{2}$ contains only one interface, all results, including $\mathrm{CVD}-\mathrm{WS} \mathrm{H}_{2} / 2 \mathrm{D}$ $\mathrm{BN} / \mathrm{SiO}_{2}, \mathrm{PT}-\mathrm{WSe} \mathrm{C}_{2} / 2 \mathrm{D}-\mathrm{BN} / \mathrm{SiO}_{2}$, and CVD-MoSe $2 / 2 \mathrm{D}-\mathrm{BN} / \mathrm{SiO}_{2}$ (Supplementary Fig. 30), exhibit an improved thermal dissipation in the case of the channel/2D-BN/SiO ${ }_{2}$. Compared with that of CVD-WSe $2 / \mathrm{SiO}_{2}$ and $\mathrm{CVD}-\mathrm{MoSe}_{2} / \mathrm{SiO}_{2}$, the interfacial thermal resistance of CVD-WSe $2 / 2 \mathrm{D}-\mathrm{BN} / \mathrm{SiO}_{2}$ (Fig. 7a) and CVD-MoSe $\mathrm{C}_{2} /$ $2 \mathrm{D}-\mathrm{BN} / \mathrm{SiO}_{2}$ (Supplementary Fig. 31 ) reduces by $(4.55 \pm 0.25) \times$ $10^{-8}$ and $(1.21 \pm 0.20) \times 10^{-7} \mathrm{~m}^{2} \mathrm{~K} \mathrm{~W}^{-1}$, respectively (Fig. $7 \mathrm{c}$ ). In the case of the $\mathrm{WSe}_{2}$, to avoid the difference in sample quality on different growth substrates ${ }^{48}$, we measured PT-WSe $2 / 2 \mathrm{D}-\mathrm{BN} / \mathrm{SiO}_{2}$ and $\mathrm{PT}-\mathrm{WSe} \mathrm{SiO}_{2}$ by differential $3 \omega$ method. The measurement shows reduced interfacial thermal resistance of $\mathrm{PT}-\mathrm{WS} \mathrm{e}_{2} / 2 \mathrm{D}-\mathrm{BN} /$ $\mathrm{SiO}_{2}$ by $(1.2 \pm 0.20) \times 10^{-8} \mathrm{~m}^{2} \mathrm{~K} \mathrm{~W}^{-1}$ compared with PT-WSe $\mathrm{H}_{2} /$ $\mathrm{SiO}_{2}$ (Supplementary Fig. 32). The calculated thermal resistance $\left(4.2 \times 10^{-8}\right.$ or $\left.1.1 \times 10^{-7} \mathrm{~m}^{2} \mathrm{~K} \mathrm{~W}^{-1}\right)$ by differential $3 \omega$ method corresponds to the sum of the substrate thermal resistance and the interfacial thermal resistance of $\mathrm{CVD}-\mathrm{WS} \mathrm{S}_{2} / 2 \mathrm{D}-\mathrm{BN} / \mathrm{SiO}_{2}$ or $\mathrm{CVD}$ $\mathrm{MoSe}_{2} / 2 \mathrm{D}-\mathrm{BN} / \mathrm{SiO}_{2}$, respectively. Thus, the interfacial thermal resistance of CVD-WSe $2 / 2 \mathrm{D}-\mathrm{BN} / \mathrm{SiO}_{2}$ and CVD-MoSe $2 / 2 \mathrm{D}-\mathrm{BN} /$ $\mathrm{SiO}_{2}$ is lower than $4.2 \times 10^{-8}$ and $1.1 \times 10^{-7} \mathrm{~m}^{2} \mathrm{~K} \mathrm{~W}^{-1}$ (Supplementary Note 5), showing better thermal dissipation compared with the results of graphene $/ \mathrm{SiO}_{2}\left(1.24-5.56 \times 10^{-8} \mathrm{~m}^{2} \mathrm{~K} \mathrm{~W}^{-1}\right)^{49}$, $\mathrm{MoSe}_{2} / \mathrm{Au} / \mathrm{SiO}_{2}\left(100-1000 \times 10^{-8} \mathrm{~m}^{2} \mathrm{KW}^{-1}\right)^{51}$, etc.
Moreover, one benefit of ne-PECVD is that the conformal 2D$\mathrm{BN}$ avoids impurities, interstices, or incompact contacts, which normally exist in post-growth transferred 2D-BN produced by CVD. The direct CVD growth of $\mathrm{WSe}_{2}$ on $2 \mathrm{D}-\mathrm{BN}$ provides strong interlayer coupling ${ }^{46}$. As a result of the clean and tightly contacted interface, the differential $3 \omega$ measurement (Fig. $7 \mathrm{~d}$ ) shows that the interfacial thermal resistance of $\mathrm{PT}-\mathrm{WS} \mathrm{e}_{2} / 2 \mathrm{D}-\mathrm{BN}$ (prepared by ne-PECVD) $/ \mathrm{SiO}_{2}$ decreased by $1 \times 10^{-7} \mathrm{~m}^{2} \mathrm{~K} \mathrm{~W}^{-1}$, compared with $\mathrm{PT}-\mathrm{WS} \mathrm{S}_{2} / 2 \mathrm{D}-\mathrm{BN}$ (post-growth transferred CVD $2 \mathrm{D}-\mathrm{BN}) / \mathrm{SiO}_{2}$, indicating the significance of ne-PECVD $2 \mathrm{D}-\mathrm{BN}$ with conformal van-der-Walls interface in device thermal management.

Molecular dynamics simulation of interfacial thermal dissipation. The discrepancy in thermal dissipation should be related to the roughness of the interface that an additional layer of 2D-BN could help the $\mathrm{WSe}_{2}$ (or $\mathrm{MoSe}_{2}$ ) to conform onto the $\mathrm{SiO}_{2}$ surface, resulting in a reduced roughness and interface thermal resistance ${ }^{18,49}$. To clarify the mechanism, we compare the interfacial thermal resistance for $\mathrm{WSe}_{2} / \mathrm{SiO}_{2}(R 1)$ and $\mathrm{WSe}{ }_{2} / 2 \mathrm{D}-\mathrm{BN} /$ $\mathrm{SiO}_{2}(R 2)$ under different substrate surface roughness conditions by molecular dynamics (MD) simulations (Supplementary Note 6, Supplementary Fig. 33). Because of the broadened vibrational frequency distribution ${ }^{52}$, the $2 \mathrm{D}$-BN layer works as an external material that can better fit the vibrational spectrum between $\mathrm{SiO}_{2}$ substrate and $\mathrm{WSe}_{2}$ layer. Therefore, the insertion of $2 \mathrm{D}-\mathrm{BN}$ layer can reduce the interfacial thermal resistance, regardless of the substrate roughness. In the MD simulations, the size of the amorphous $\mathrm{SiO}_{2}$ substrate is $12.4 \mathrm{~nm} \times 12.4 \mathrm{~nm} \times 4$ $\mathrm{nm}$, and the monolayer $2 \mathrm{D}-\mathrm{BN}$ and $\mathrm{WSe}_{2}$ conformally cover the substrate. In order to simulate the practical surface roughness of $\mathrm{SiO}_{2}$ substrate, we randomly removed surface atoms to form holes with a diameter of $R_{a}$, as shown in Fig. 7e. For the smooth substrate, $R 1$ is reduced by almost $50 \%$ after inserting a $2 \mathrm{D}-\mathrm{BN}$ layer. More interestingly, $R 1$ increases rapidly with the substrate roughness as a result of the enhanced rough surface scattering, 
a

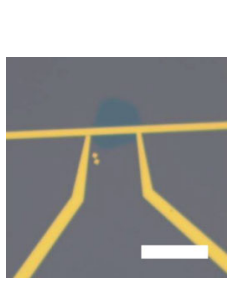

e

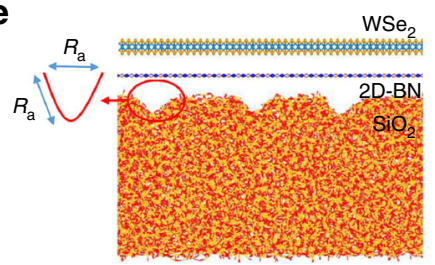

$\mathbf{f}$

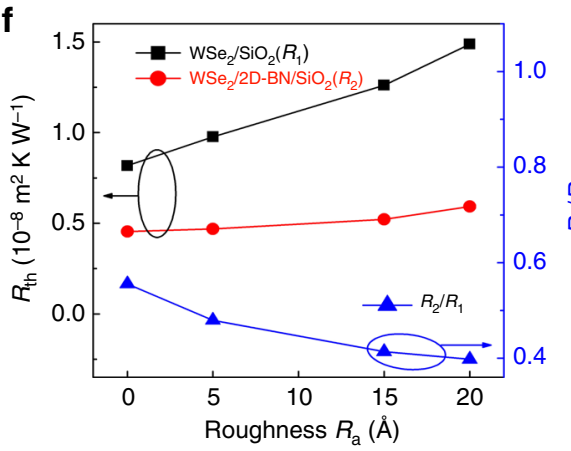

C

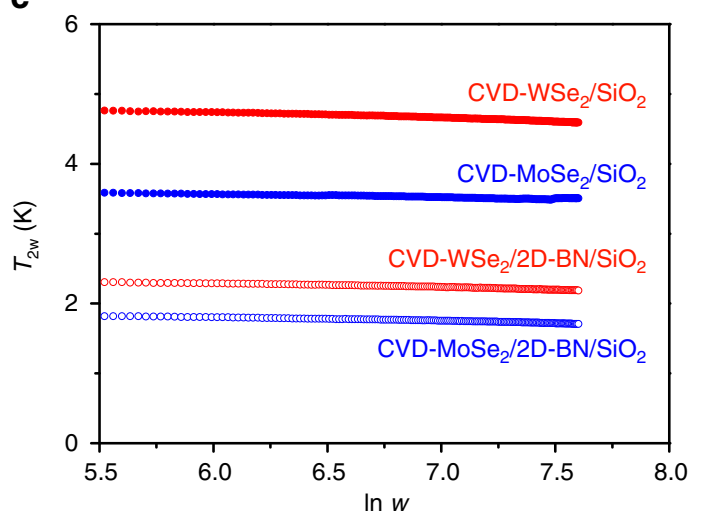

d

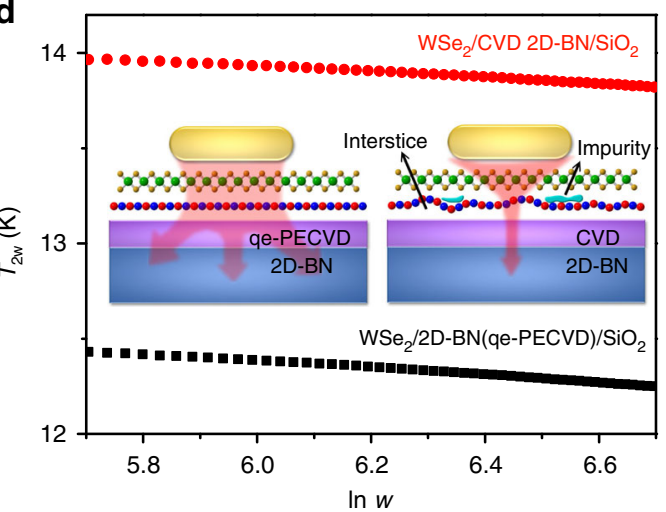

Fig. 7 Differential $3 \omega$ measurement and molecular dynamics (MD) simulation of the interfacial thermal resistance. a Optical image of a CVD-WSe 2 device for differential $3 \omega$ measurement. b Schematic images of the devices for $3 \omega$ measurement, in which $\mathrm{Au} / \mathrm{Cr}$ is used as both the Joule heat source (current with a frequency of $w$ ) and the detection electrode (electrical signal with a frequency of $3 w$ ). c $T_{2 \omega}$ vs. In $\omega$ for CVD-WSe $/ \mathrm{SiO}_{2}(\mathrm{red}$ solid), CVD-WSe $/$ $2 \mathrm{D}-\mathrm{BN} / \mathrm{SiO}_{2}$ (red open), CVD-MoSe $2 / \mathrm{SiO}_{2}$ (blue solid), and CVD-MoSe $2 / 2 \mathrm{D}-\mathrm{BN} / \mathrm{SiO}_{2}$ (blue open) interfaces. d $T_{2 \omega} \mathrm{Vs}$. In $\omega$ for $\mathrm{WSe} / 2 \mathrm{D}-\mathrm{BN} / \mathrm{SiO}{ }_{2}$ interface. The $2 \mathrm{D}-\mathrm{BN} / \mathrm{SiO}_{2}$ substrate was prepared by ne-PECVD (black) or transferring CVD $2 \mathrm{D}-\mathrm{BN}$ on $\mathrm{SiO}_{2} / \mathrm{Si}(\mathrm{red})$. e WSe $/ 2 \mathrm{D}-\mathrm{BN} / \mathrm{SiO} / 2 \mathrm{hybrid}$ system used in MD simulation. $\mathbf{f}$ The effect of the substrate roughness $\left(R_{\mathrm{a}}\right)$ on the interfacial thermal resistance $\left(R_{\mathrm{th}}\right)$ for $\mathrm{WSe} / 2 / \mathrm{SiO}_{2}$ and WSe $/ 2 \mathrm{D}-\mathrm{BN} /$ $\mathrm{SiO}_{2}$ hybrid systems from MD simulation. The scale bar in a is $20 \mu \mathrm{m}$

while the interfacial heat conduction is protected by the $2 \mathrm{D}-\mathrm{BN}$ layer against the substrate roughness, leading to the almost constant value of $R 2$. As a result, the improvement in the interfacial heat conduction via the insertion of $2 \mathrm{D}-\mathrm{BN}$ layer is even more pronounced at larger surface roughness (Fig. 7f, Supplementary Fig. 34). With $2 \mathrm{~nm}$ substrate roughness, $R 1$ is reduced by $60 \%$, which agrees well with our experimental results.

\section{Discussion}

In this article, we directly modify the dielectric interface with poly-crystalline mono-/few-layer $2 \mathrm{D}-\mathrm{BN}$ with domain size around $20-200 \mathrm{~nm}$ at a temperature as low as $300^{\circ} \mathrm{C}$. To the best of our knowledge, it is the lowest reported temperature for growing 2D-BN. The conformal growth on $3 \mathrm{D}$ surface is important for microelectronics manufacturing, however it is still difficult to be realized by existing $2 \mathrm{D}-\mathrm{BN}$ preparation methods. Using ne-PECVD, large-area 2D-BN with desired thickness is directly grown on not only flat but also 3D inert surface without using metal catalyst. This method avoids the post-growth transfer process required in normal CVD process, forming a clean conformal van-der-Waals dielectric interface.

After modification, the as-grown 2D-BN was directly used to grow CVD-WSe $\mathrm{C}_{2}$ for FET devices. The clean flat dielectric interface has low density of dangling bonds, charge impurities and charge traps, which lead to improved mobility compared with that of CVD-WSe 2 grown on bare $\mathrm{SiO}_{2} / \mathrm{Si}$. MD simulation shows that the $2 \mathrm{D}-\mathrm{BN}$ can better bridge the vibrational spectrum across the dielectric interface, and protect the interfacial heat conduction against substrate roughness. Thus, the clean and conformal $2 \mathrm{D}-\mathrm{BN}$ produced by ne-PECVD not only improves the device mobility but also reduces interfacial thermal resistance. After ne-PECVD modification, the interfacial thermal resistance of CVD-WSe $2 / \mathrm{SiO}_{2}$ and CVD-MoSe $2 / \mathrm{SiO}_{2}$ decreases by $4.55 \times$ $10^{-8}$ and $1.21 \times 10^{-7} \mathrm{~m}^{2} \mathrm{~K} \mathrm{~W}^{-1}$ to a value lower than $4.2 \times 10^{-8}$ and $1.1 \times 10^{-7} \mathrm{~m}^{2} \mathrm{~K} \mathrm{~W}^{-1}$, respectively. As a result, the saturated power intensity of the CVD-WSe $\mathrm{CHT}_{2}$ FEcreases by several folds up to $4.23 \times 10^{3} \mathrm{~W} \mathrm{~cm}^{-2}$. More importantly, the dielectric interface with ne-PECVD 2D-BN exhibits lower interfacial thermal resistance than that with post-growth transferred CVD 2D-BN, indicating the great importance of the clean conformal interface in efficient thermal dissipation. Therefore, the ne-PECVD modification results in electrical devices with both high performance and power stability, compared with that on a bare $\mathrm{SiO}_{2}$ or CVD 2D-BN dielectric surface. These, as well as the advantages of low modification temperature, atomically smooth and clean surface, no requirement of post-growth transfer, conformal growth on 3D surface, capability for scaling up and industrial compatibility with microelectronic process, make this approach an ideal dielectric interface modification methodology for future micro/ nanoelectronics.

\section{Methods}

Growth of 2D-BN. Continuous 2D-BN films were produced on $\mathrm{SiO}_{2} / \mathrm{Si}$ in a PECVD system. Ammonia borane $\left(\mathrm{BH}_{3}-\mathrm{NH}_{3}\right.$, Sigma-Aldrich), which was used as 
the precursor, was placed in an isolated semi-enclosed quartz tube in $T 1$ zone. Semi-enclosed quartz tube was used to reduce the precursor feeding rate and to obtain a steady precursor supply. A clean $\mathrm{SiO}_{2} / \mathrm{Si}$ was placed in $T 2$ zone and heated to $500{ }^{\circ} \mathrm{C}$ in a constant $\mathrm{Ar} / \mathrm{H}_{2}$ flow of $100 \mathrm{sccm} / 10 \mathrm{sccm}$ ( $\left.860 \mathrm{mTorr}\right)$. After the $\mathrm{T} 2$ reached $500{ }^{\circ} \mathrm{C}, 20 \mathrm{mg}$ ammonia borane was heated up to $110^{\circ} \mathrm{C}$. Meanwhile, the plasma generator $(30 \mathrm{~W})$ was opened, and the plasma flame filled the whole quartz tube, resulting in high efficient growth of 2D-BN. After growth for 30-60 min, the furnace was fast cooled to room temperature.

Characterization. The 2D-BN and WSe $e_{2}$ samples were measured by AFM (Multimode 8, Bruker, tapping mode), high-resolution TEM (Tecnai G2 F20 S-Twin, acceleration voltage: $200 \mathrm{kV}$ ), EDS (equipped on TEM), optical microscopy (DM2500P, Leica), XPS (Perkin-Elmer PHI 5300 with $250 \mathrm{~W}$ Mg Ka source, $1253.6 \mathrm{eV}$ ), Raman spectra (HORIBA XploRA, $532 \mathrm{~nm}$ laser), UV-vis absorption spectrophotometer (Perkin-Elmer, Lambda35), and field-emission SEM (ZEISS, Ultra 55). The thermal images were measured by using a SThM probe (VITA-DM) mounted in the tip cantilever of Bruker Dimension Edge AFM (Supplementary Note 7, Supplementary Fig. 35). For TEM, AFM, or STM measurements, PMMA was spin-coated on the $2 \mathrm{D}-\mathrm{BN} / \mathrm{SiO}_{2} / \mathrm{Si}$, and then the PMMA/2D-BN film was lift off from $\mathrm{SiO}_{2} / \mathrm{Si}$ by etching in $20 \%$ hydrofluoric acid. The PMMA/2D-BN film was rinsed in deionized water and transferred to the TEM grids, $\mathrm{SiO}_{2} / \mathrm{Si}$, or HOPG, respectively. Finally, the PMMA was removed by either immersion in acetone or heating at $400^{\circ} \mathrm{C}$ in $\mathrm{Ar}$ atmosphere. STM measurements were carried out in a custom-built multi-chamber ultrahigh vacuum system housing an Omicron LTSTM in the analysis chamber with a base pressure better than $1.0 \times 10^{-10} \mathrm{mbar}$. All STM images were recorded in constant current mode at liquid nitrogen temperature $(77 \mathrm{~K})$ using electrochemically etched tungsten (W) tips. The STS data were acquired using a lock-in amplifier by applying a small sinusoidal modulation to the tip bias voltage (typically $3 \mathrm{~V}$ at $600 \mathrm{~Hz}$ ). All STM images were processed using $\mathrm{WS}_{\mathrm{x}} \mathrm{M}$.

Device fabrication and measurement. CVD-WSe $\mathrm{W}_{2}$ was directly grown on 2D$\mathrm{BN} / \mathrm{SiO}_{2} / \mathrm{Si}$ by CVD. PT-WSe 2 was prepared by post-growth transfer of CVD$\mathrm{WSe}_{2}$ to $2 \mathrm{D}-\mathrm{BN} / \mathrm{SiO}_{2} / \mathrm{Si}$ using PMMA. After that, the source-drain electrodes (5/ $50 \mathrm{~nm} \mathrm{Cr} / \mathrm{Au}$ or $50 \mathrm{~nm} \mathrm{Au}$ ) were patterned on the sample by electron beam lithography and thermal deposition (Kurt J. Lesker). To obtain a better contact between the sample and the electrodes, thermal-annealing or current-annealing was performed. The electrical measurement was carried out in air at room temperature by a probe station (EVERBING, PE-4) and a semiconductor analyzer (Keysight B1500A). Details of the differential $3 \omega$ measurement were discussed in Supplementary Note 5.

\section{Data availability}

The data that support the findings of this study are available within the article and its Supplementary Information File or available from the corresponding author.

Received: 21 June 2017 Accepted: 5 February 2019

Published online: 13 March 2019

\section{References}

1. Wang, Q. H., Kalantar-Zadeh, K., Kis, A., Coleman, J. N. \& Strano, M. S. Electronics and optoelectronics of two-dimensional transition metal dichalcogenide. Nat. Nanotechnol. 7, 699-712 (2012).

2. $\mathrm{Yu}, \mathrm{W}$. J. et al. Highly efficient gate-tunable photocurrent generation in vertical heterostructures of layered materials. Nat. Nanotechnol. 8, 952-958 (2013).

3. Allain, A. \& KisElectron, A. Electron and hole mobilities in single layer $\mathrm{WSe}_{2}$. ACS Nano 8, 7180-7185 (2014).

4. Campbell, P. M. et al. Field-effect transistors based on wafer-scale,highly uniform few-layer p-type $\mathrm{WSe}_{2}$. Nanoscale 8, 2268-2276 (2016).

5. Lin, Y. et al. Realizing large-scale, electronic-grade two dimensional semiconductors. ACS Nano 12, 965-975 (2018).

6. Chiritescu, C. et al. Ultralow thermal conductivity in disordered, layered WSe crystals. Science 315, 351-353 (2007).

7. Wang, S., Wang, X. \& Warner, J. H. All chemical vapor deposition growth of $\mathrm{MoS}_{2}: h$-BN vertical van der Waals heterostructures. ACS Nano 9, 5246-5254 (2015).

8. Okada, M. et al. Direct chemical vapor deposition growth of $\mathrm{WS}_{2}$ atomic layers on hexagonal boron nitride. ACS Nano 8, 8273-8277 (2014).

9. Dean, C. R. et al. Boron nitride substrates for high-quality graphene electronics. Nat. Nanotechnol. 5, 722-726 (2010).

10. Iqbal, M. W. et al. High-mobility and air-stable single-layer $\mathrm{WS}_{2}$ field-effect transistors sandwiched between chemical vapor deposition-grown hexagonal BN films. Sci. Rep. 5, 10699 (2015).
11. Joo, M. et al. Understanding coulomb scattering mechanism in monolayer $\mathrm{MoS}_{2}$ channel in the presence of $h$-BN buffer layer. ACS Appl. Mater. Interfaces 9, 5006-5013 (2017).

12. Kim, K. K., Lee, H. S. \& Lee, Y. H. Synthesis of hexagonal boron nitride heterostructures for 2D van der Waals electronics. Chem. Soc. Rev. 47, 6342-6369 (2018).

13. Ji, H. et al. Suppression of interfacial current fluctuation in $\mathrm{MoTe}_{2}$ transistors with different dielectrics. ACS Appl. Mater. Interfaces 8, 19092-19099 (2016).

14. Hui, F. et al. On the use of two dimensional hexagonal boron nitride as dielectric. Micro. Eng. 163, 119-133 (2016).

15. Kang, S. J. et al. Organic field effect transistors based on graphene and hexagonal boron nitride heterostructures. Adv. Funct. Mater. 24, 5157-5163 (2014).

16. Moore, A. L. \& Shi, L. Emerging challenges and materials for thermal management of electronics. Mater. Today 17, 163-174 (2014).

17. Pop, E. Energy dissipation and transport in nanoscale devices. Nano Res. 3 , 147-169 (2010).

18. $\mathrm{Li}$, X. et al. Thermal conduction across a boron nitride and $\mathrm{SiO}_{2}$. J. Phys. D Appl. Phys. 50, 104002 (2017).

19. Li, F., Nathan, A., Wu, Y. \& Ong, B. S. Dielectric Interface Engineering (Wiley, Weinheim, 2011)

20. Kaur, S., Raravikar, N., Helms, B. A., Prasher, R. \& Ogletree, D. F. Enhanced thermal transport at covalently functionalized carbon nanotube array interfaces. Nat. Commun. 5, 3082 (2014).

21. Losego, M. D., Grady, M. E., Sottos, N. R., Cahill, D. G. \& Braun, P. V. Effects of chemical bonding on heat transport across interfaces. Nat. Mater. 11, 502-506 (2012)

22. Yin, J. et al. Boron nitride nanostructures: fabrication, functionalization and applications. Small 12, 2942-2968 (2016).

23. Wang, C. R. et al. Superior thermal conductivity in suspended bilayer hexagonal boron nitride. Sci. Rep. 6, 25334 (2016).

24. Uchida, Y. et al. Controlled growth of large-area uniform multilayer hexagonal boron nitride as an effective 2D substrate. ACS Nano 12, 6236-6244 (2018).

25. Kim, S. M. et al. Synthesis of large-area multilayer hexagonal boron nitride for high material performance. Nat. Commun. 6, 8662 (2015).

26. Haigh, S. J. et al. Cross-sectional imaging of individual layers and buried interfaces of graphene-based heterostructures and superlattices. Nat. Mater. 11, 764-767 (2012).

27. Kim, K. K. et al. Synthesis of monolayer hexagonal boron nitride on $\mathrm{Cu}$ foil using chemical vapor deposition. Nano Lett. 12, 161-166 (2012).

28. Shi, Y. et al. Synthesis of few-layer hexagonal boron nitride thin film by chemical vapor deposition. Nano Lett. 10, 4134-4139 (2010).

29. Lu, G. Y. et al. Synthesis of large single-crystal hexagonal boron nitride grains on $\mathrm{Cu}-\mathrm{Ni}$ alloy. Nat. Commun. 6, 6160 (2015).

30. Song, X. J. et al. Chemical vapor deposition growth of large-scale hexagonal boron nitride with controllable orientation. Nano Res. 8, 3164-3176 (2015).

31. Behura, S., Nguyen, P., Che, S., Debbarma, R. \& Berry, V. Large-area, transferfree, oxide-assisted synthesis of hexagonal boron nitride films and their heterostructures with $\mathrm{MoS}_{2}$ and WS 2 . J. Am. Chem. Soc. 137, 13060-13065 (2015).

32. Jang, A.-R. et al. Wafer-scale and wrinkle-free epitaxial growth of singleorientated multilayer hexagonal boron nitride on sapphire. Nano Lett. 16, 3360-3366 (2016).

33. El-Yado uni, A. et al. Investigation of optical and electro optical properties of hexagonal boron nitride thin films deposited by PECVD technique. Opt. Mater. 17, 319-322 (2001).

34. Carreno, M. N. P., Bottecchia, J. P. \& Pereyra, I. Low temperature plasma enhanced chemical vapour deposition boron nitride. Thin Solid Films 308309, 219-222 (1997).

35. Vilcarromero, J., Carreno, M. N. P. \& Pereyra, I. Mechanical properties of boron nitride thin films obtained by RF-PECVD at low temperatures. Thin Solid Films 373, 273-276 (2000).

36. Drost, R., Hämäläinen, S., Demonchaux, T., Seitsonen, A. \& Liljeroth, P. Epitaxial hexagonal boron nitride on $\operatorname{Ir}(111)$ : a work function template. Phys. Rev. B 89, 235429 (2014). F.

37. Ugeda, M. M. et al. Giant bandgap renormalization and excitonic effects in a monolayer transition metal dichalcogenide semiconductor. Nat. Mater. 13, 1091-1095 (2014)

38. Pierson, H. O. Boron nitride composites by chemical vapor deposition. J. Compos. Mater. 9, 228-240 (1975).

39. Reinke, P., Oelhafen, P., Feldermann, H., Ronning, C. \& Hofsass, H. Hydrogen-plasma etching of ion beam deposited c-BN films: an in situ investigation of the surface with electron spectroscopy. J. Appl. Phys. 88, 5597-5604 (2000)

40. Schaffnit, C., Thomas, L. \& Rossi, F. Etching of boron nitride in radio frequency plasmas. J. Vac. Sci. Technol. A 15, 2816-2819 (1997).

41. Zeng, H. et al. "White graphenes": boron nitride nanoribbons via boron nitride nanotube unwrapping. Nano Lett. 10, 5049-5055 (2010). 
42. Wei, D. et al. Critical crystal growth of graphene on dielectric substrates at low temperature for electronic devices. Angew. Chem. Int. Ed. 125, 14371-14376 (2013).

43. Mukherjee, R. \& Bhowmick, S. Edge stabilities of hexagonal boron nitride nanoribbons: a first-principles study. J. Chem. Theory Comput. 7, 720-724 (2011).

44. Zhao, S. et al. Strong room-temperature emission from defect states in CVDgrown $\mathrm{WSe}_{2}$ nanosheets. Nano Res. 11, 3922-3930 (2018).

45. Wehling, T. O., Katsnelson, M. I. \& Lichtenstein, A. I. Adsorbates on graphene: impurity states and electron scattering. Chem. Phys. Lett. 476, 125-134 (2009).

46. Zhang, J. et al. Observation of strong interlayer coupling in $\mathrm{MoS}_{2} / \mathrm{WS}_{2}$ heterostructures. Adv. Mater. 28, 1950-1956 (2016).

47. Lin, T.-W. et al. Converting graphene oxide monolayers into boron carbonitride nanosheets by substitutional doping. Small 8, 1384-1391 (2012).

48. Eichfeld, S. M. et al. Highly scalable, atomically thin WSe2 grown via metal-organic chemical vapor deposition. ACS Nano 9, 2080-2087 (2015).

49. Chen, Z., Jang, W., Bao, W., Lau, C. N. \& Dames, C. Thermal contact resistance between graphene and silicon dioxide. Appl. Phys. Lett. 95, 161910 (2009).

50. Majumdar, A. Scanning thermal microscopy. Annu. Rev. Mater. Sci. 29, 505-585 (1999).

51. Zhang, X. et al. Measurement of lateral and interfacial thermal conductivity of single- and bilayer $\mathrm{MoS}_{2}$ and $\mathrm{MoSe}_{2}$ using refined optothermal Raman technique. ACS Appl. Mater. Interfaces 7, 25923-25929 (2015).

52. Lindsay, L. \& Broido, D. A. Enhanced thermal conductivity and isotope effect in single-layer hexagonal boron nitride. Phys. Rev. B 84, 155421 (2011).

\section{Acknowledgements}

This work was supported by the National Natural Science Foundation of China (51773041, 11890703, 21544001, 21603038, 11404329, 51506153, 11334007, and 11674245), Shanghai Committee of Science and Technology in China (18ZR1404900 and 17ZR1448000), the Strategic Priority Research Program of the Chinese Academy of Sciences (XDB30000000), the Natural Science Foundation Project of CQ CSTC (CSTC2014jcyjjq50004), National Youth 1000 Talents Program in China, and State Key Laboratory of Molecular Engineering of Polymers.

\section{Author contributions}

D.C.W. conceived and designed the experiments. D.C.W. supervised this project. D.L., X.C., J.Y. and D.P.W. prepared the sample and did AFM, SEM, TEM, and XPS. D.C.W., Y.Z. and A.W. measured STM and STS. D.L., K.Y. and X.C. did the electron beam lithography and prepared $\mathrm{MoSe}_{2}$. Z.J. prepared the WSe $\mathrm{W}_{2}$. D.P.W. prepared $\mathrm{SiO}_{2} / \mathrm{S}$ substrate with 3D structure. D.C.W., D.L., Z.J., C.Z. and D.P.W. did electrical measurement. Y.Y. and X.X. did SThM and differential $3 \omega$ measurement. Z.Z. and J.C. did the MD simulation. Y.W. and Y.L. calculated the edge energy. D.C.W. and D.L. prepared the manuscript. All authors commented on the manuscript.

\section{Additional information}

Supplementary Information accompanies this paper at https://doi.org/10.1038/s41467019-09016-0.

Competing interests: The authors declare no competing interests.

Reprints and permission information is available online at http://npg.nature.com/ reprintsandpermissions/

Journal peer review information: Nature Communications thanks Ravi Sundaram and the other anonymous reviewer(s) for their contribution to the peer review of this work.

Publisher's note: Springer Nature remains neutral with regard to jurisdictional claims in published maps and institutional affiliations.

cc (i) Open Access This article is licensed under a Creative Commons Attribution 4.0 International License, which permits use, sharing, adaptation, distribution and reproduction in any medium or format, as long as you give appropriate credit to the original author(s) and the source, provide a link to the Creative Commons license, and indicate if changes were made. The images or other third party material in this article are included in the article's Creative Commons license, unless indicated otherwise in a credit line to the material. If material is not included in the article's Creative Commons license and your intended use is not permitted by statutory regulation or exceeds the permitted use, you will need to obtain permission directly from the copyright holder. To view a copy of this license, visit http://creativecommons.org/ licenses/by/4.0/.

(C) The Author(s) 2019 